\title{
Propulsion Engineering Study for
}

\section{Small-Scale Mars Missions}

\author{
John Whitehead
}

September 12, 1995

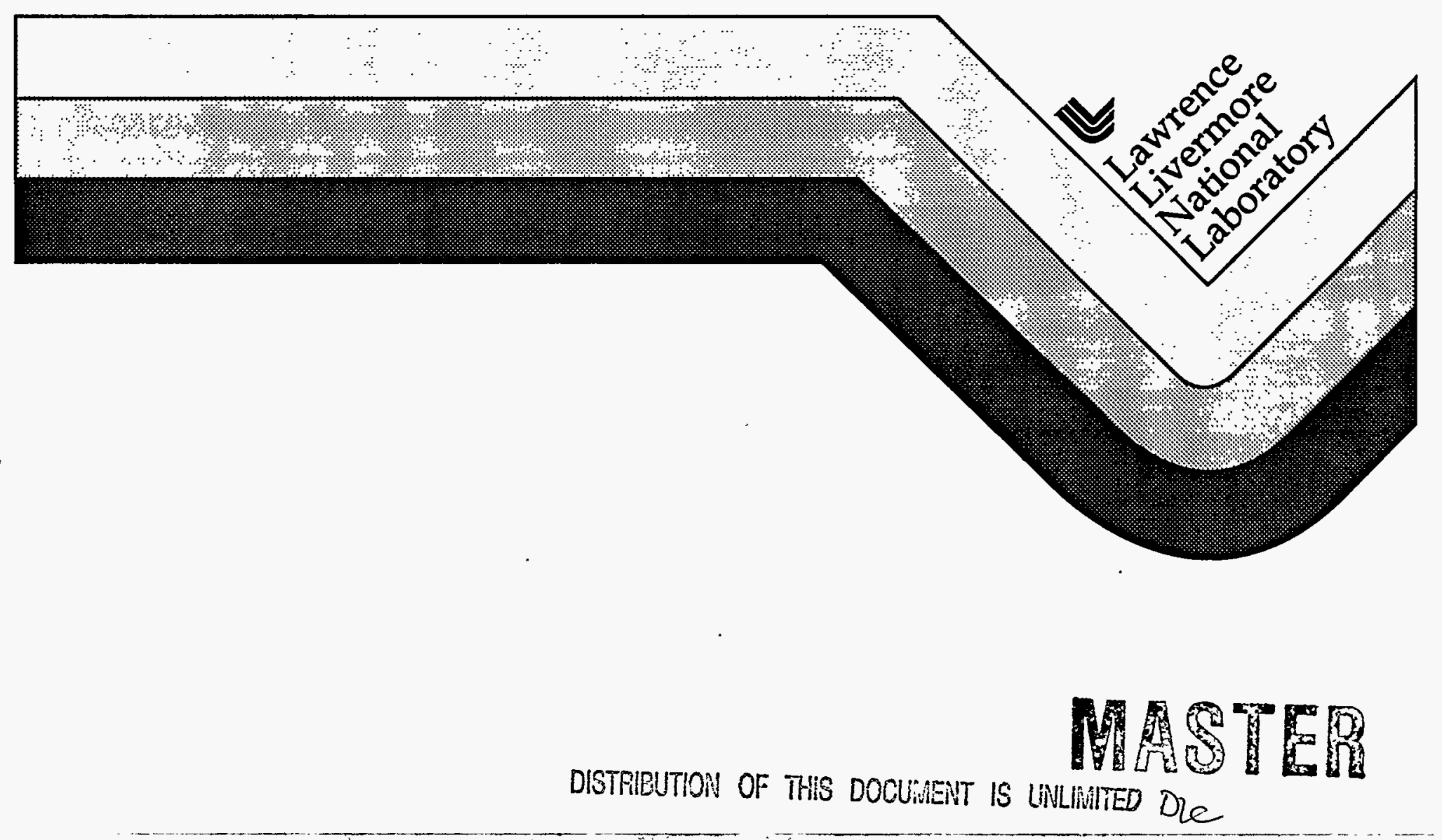




\section{DISCLAIMER}

This document was prepared as an account of work sponsored by an agency of the United States Government. Neither the United States Government nor the University of California nor any of their employees, makes any warranty; express or implied, or assumes any legal liability or responsibility for the accuracy, completeness, or usefulness of any information, apparatus, product, or process disclosed, or represents that its use would not infringe privately owned rights. Reference herein to any specific commercial products, process, or service by trade name, trademark, manufacturer, or otherwise, does not necessarily constitute or imply its endorsement, recommendation, or favoring by the United States Government or the University of California. The views and opinions, of authors expressed herein do not necessarily state or reflect those of the United States Government or the University of California, and shall not be used for advertising or product endorsement purposes.

Work performed under the auspices of the U.S. Department of Energy by Lawrence Livermore National Laboratory under Contract W-7405-Eng-48. 


\title{
Propulsion Engineering Study for Small-Scale Mars Missions
}

\author{
Prepared by: \\ Dr. John Whitehead \\ O-Division \\ Physics and Space Technology Directorate \\ Lawrence Livermore National Laboratory
}

Final Report to:

Larry Lemke

Branch Chief

Advanced Projects Branch

Space Projects Division

NASA Ames Research Center

September 12, 1995 


\section{Summary}

Rocket propulsion options for small-scale Mars missions are presented and compared, particularly for the terminal landing maneuver and for sample return. Mars landing has a low propulsive $\Delta v$ requirement on a $\sim 1$-minute time scale, but at a high acceleration. High thrust/weight liquid rocket technologies, or advanced pulse-capable solids, developed during the past decade for missile defense, are therefore more appropriate for small Mars landers than are conventional space propulsion technologies. The advanced liquid systems are characterized by compact lightweight thrusters having high chamber pressures and short lifetimes.

Blowdown or regulated pressure-fed operation can satisfy the Mars landing requirement, but hardware mass can be reduced by using pumps. Aggressive terminal landing propulsion designs can enable post-landing hop maneuvers for some surface mobility. The Mars sample return mission requires a small high performance launcher having either solid motors or miniature pump-fed engines.

Terminal propulsion for $100 \mathrm{~kg}$ Mars landers is within the realm of flight-proven thruster designs, but custom tankage is desirable. Landers on a $10 \mathrm{~kg}$ scale also are feasible, using technology that has been demonstrated but not previously flown in space. The number of sources and the selection of components are extremely limited on this smallest scale, so some customized hardware is required. A key characteristic of kilogram-scale propulsion is that gas jets are much lighter than liquid thrusters for reaction control. The mass and volume of tanks for inert gas can be eliminated by systems which generate gas as needed from a liquid or a solid, but these have virtually no space flight history.

Mars return propulsion is a major engineering challenge; earth launch is the only previouslysolved propulsion problem requiring similar or greater performance. Mars in-situ propellant production is a promising concept which offers the potential to reduce the mass which must be transported from earth. However, the use of in-situ propellants does not mitigate the difficulty of designing the return vehicle's propulsion system.

Piston pumps enable launch vehicle performance ratios (propellant mass fraction and thrust/weight) on a tiny scale, so they offer new possibilities for smaller, less expensive Mars sample return vehicles without the scale-down limitations of turbopumps. This flightdemonstrated technology is similarly preferred for lunar landing and return, which demand significant $\Delta \mathrm{v}$ and acceleration.

Systems which use pumps require neither gas bottles nor extra tank ullage, thus reducing volume requirements (e.g. inside a Mars lander aeroshell), as well as reducing propulsion hardware mass. Range safety concerns related to pressure can be eliminated, by remaining at low pressure until after earth launch. There are two different ways to use pumps, neither of which has a known space flight history on a small scale. For low $\Delta \mathrm{v}$ missions such as Mars landing, a simple pump can feed a gas generator to make tank pressurant. Alternatively, high performance pumps can be used to directly feed high pressure thrusters from lightweight low pressure tanks, to minimize hardware mass. Both types of systems use gas generators, so it is straightforward to also deliver gas to reaction control jets.

Less toxic propellants mitigate safety hazards, which can reduce the development and testing costs of advanced systems that are not yet mature. In flight programs, nontoxic propellants would enhance launch range safety, and would permit extensive terrestrial testing of complete vehicles, including landing and hopping maneuvers. Therefore, investment in advanced technology using minimally hazardous propellants is recommended to ensure ultimate availability for future missions. Developing tiny nontoxic systems (e.g. for $10 \mathrm{~kg}$ Mars landers) is a logical place to begin, both because development costs would be low and because conventional technology fits awkwardly, at best, into this application niche. 


\section{Table of Contents}

Summary

Table of Contents

List of Figures

Introduction

Acknowledgment

Contract Statement of Work

Mars soft landing_propulsion requirements 5

Mars surface mobility-propulsive hopping $\quad 8$

Mars sample return-propulsion requirements 9

Other propulsion requirements for Mars exploration $\quad 11$

Comments on propulsion technology relevant to Mars missions 12

Propulsion options for a $100 \mathrm{~kg}$ Mars lander $\quad 16$

Propulsion options for a $10 \mathrm{~kg}$ Mars lander $\quad 29$

Propulsion options for a $100 \mathrm{~kg}$ Mars hopper 34

Propulsion for Mars sample return $\quad 35$

General propulsion design issues $\quad 39$

Review of LLNL pumped propulsion as flown on ASTRID 41

The case for nontoxic propellants $\quad 42$

References cited 44

\section{List of Figures}

1. Propulsive Requirements \& Spacecraft Capabilities

2. Chemical Propulsion Applicable Technologies

3. Rocket Engine Pump Performance 1

4. Rocket Engine Pump Performance 2

5. Mars Landing Propulsion for a $100 \mathrm{~kg}$ Vehicle

6. More Mars Landing Propulsion for a $100 \mathrm{~kg}$ Vehicle

7. Mars Landing Propulsion for a $10 \mathrm{~kg}$ Vehicle

8. First stage options for a $100 \mathrm{~kg}$ Mars Launcher

9. Mars Launcher Concept using Nontoxic Propellants

\section{Introduction}

The Space Projects Division of NASA Ames requested a study of advanced rocket propulsion technology for smaller, less expensive Mars missions, including soft-landing and sample return. This effort was undertaken for Larry Lemke, Branch Chief, Advanced Projects Branch. A contract was awarded to the Lawrence Livermore National Laboratory in consideration of LLNL advances in small, high performance liquid rocket propulsion.

\section{Acknowledgment}

Helpful technical and critical comments from George P. Sutton are greatly appreciated, particularly with regard to the applicability of solid rocket technology to Mars missions. 


\section{Contract statement of work NASA purchase order \#A45547D(SLS)}

Task 1.

Describe and analyze various options for microspacecraft $(<10 \mathrm{~kg})$ propulsion systems, including both attitude control and maneuvering capability. Determine the delta-vee and thrust/weight performance capabilities of each option, and quantitatively recommend which option is most appropriate over a continuous spectrum of these performance parameters. Additional performance-related items of interest are thrust duty cycle capability, and the fractional impulse available for attitude control and flexibility of this partitioning. For each microspacecraft propulsion system design, describe how it deviates from the state of the art in spacecraft propulsion, and whether it can be implemented using existing technology or previously tested component designs. Where possible, identify specific components by manufacturer and part number. For each option, identify new research and development efforts required for implementation, and assess the level of technical risk.

Task 2.

Based on the results of Task 1, recommend and design rocket propulsion systems for soft landing 2-kilogram payloads on Mars, with a total velocity change below 1000 meters/second, thrust approximately equal to the spacecraft's earth weight, and appropriate attitude control capability. Fabricate a non-functioning, static display model of the propulsion system.

Task 3 (as available funds permit).

Recommend methods, and describe appropriate sensor and computing hardware, for determining position, orientation, and velocity of the microlander relative to the Martian surface during the final descent phase. In cooperation with Sponsor's mission analysis efforts, assess the applicability of aerogels for descent thermal protection.

\section{Comments on statement of work}

During contract negotiations, additional interest was expressed in $100 \mathrm{~kg}$ Mars landers (1/6 to $1 / 10$ Viking scale), sample return, and the possibility of propulsive hopping for surface mobility. Due the broadened study scope, building a mockup of a particular configuration received lower priority. For example, there was interest in a mobile lander that lands directly on its wheels, as well as in a tiny lander that carries only a micrometeorology station.

The quantitative analysis described in Task 1 was oriented toward the actual requirements for Mars missions, and is less general than originally expected. 


\section{Mars soft landing-propulsion requirements}

Even though Mars has a much thinner atmosphere than earth, most of the kinetic energy of arriving landers can be shed through aerodynamic drag. In the past (Viking), the landers first entered orbit propulsively along with the orbiters. The lander included a separate propulsion system built into the aeroshell, for a deorbit maneuver and 3-axis orientation during atmospheric entry. A final propulsion system was used for terminal descent.

The deorbit (if needed) and entry RCS (reaction control system) propulsion requirements depend respectively on the orbit, and on the entry body aerodynamics including the amount of maneuvering with lift that is required. Viking, for example, used $\sim 10 \mathrm{~m} / \mathrm{s}$ of propulsive $\Delta \mathrm{v}$ for entry RCS. Alternatively, it is attractive from a propulsion design standpoint to eliminate both deorbiting $\Delta v$ and entry RCS. If only terminal landing propulsion is required, microgravity tanks (heavy and expensive) can be avoided because thrusting would begin during deceleration in a known direction (e.g. while hanging from a parachute). Direct entry at Mars permits this alternative to the Viking method.

In this case, the lander in its aeroshell would be dropped off in a known orientation by its interplanetary cruise system. The cruise components may simply be discarded on a collision course with the planet, or they may constitute a complete spacecraft that subsequently maneuvers into orbit. The landing package may be spun, to passively maintain its orientation between separation and atmospheric entry. Direct entry is planned for NASA's Mars '96 and ' 98 landers.

The terminal descent propulsion requirements for soft landing on Mars are $300-350 \mathrm{~m} / \mathrm{s}$ of $\Delta v$, with a ratio of thrust to vehicle mass equal to $10-15 \mathrm{~m} / \mathrm{sec}^{2}(\sim 3-4$ times Mars gravity, or 1-1.5 earth $\mathrm{g}$ ). The thrust must be throttleable, or pulse modulated, to obtain a thrust/mass ratio as low as $3.5 \mathrm{~m} / \mathrm{sec}^{2}$ ( $<1 \times$ Mars gravity). In addition, 3-axis attitude control is necessary during the $\sim 1$-minute terminal descent. When compared with typical spacecraft missions, this propulsion requirement is very short in operating lifetime and low in $\Delta v$, but high in acceleration. Entry RCS would require minutes of additional lifetime.

It is possible that advanced (lower mass) propulsion technology would shift the trade between parachute and propulsive deceleration, thus increasing the above $\Delta v$ requirement. Increasing the propellant load to reduce the mass of a parachute and its deployment mechanism should therefore be considered, in light of propulsion system masses presentedherein. A smaller parachute would reduce landing errors resulting from wind. A very rough estimate which bounds the problem is that the $\Delta v$ requirement would double or triple if there is no parachute at all. Of course, it should not be forgotten that a parachute orients the vehicle and settles propellant tanks.

A final possible requirement is related to propellant and plume contamination of the landing site. For example, Viking landed with high purity hydrazine, in order to avoid organic contamination which would have influenced the biology experiments. Monomethyl hydrazine (MMH), a commonly-used spacecraft fuel, would deposit organic compounds at the landing site.

\section{Viking landing scenario \& propulsion details}

The landing package mass was approximately $1100 \mathrm{~kg}$ upon separation from the Orbiter, which subsequently had approximately this same mass (Schmit et al, 1981). The $150 \mathrm{~m} / \mathrm{s}$ deorbit burn (from $\sim 4.5 \mathrm{~km} / \mathrm{s}$ orbital speed) consumed $73 \mathrm{~kg}$ hydrazine from the aeroshell propulsion system (NASA 1976), and propellant consumption continued for attitude 
control during coast and atmospheric entry. The deorbit propulsion system had a total of $85 \mathrm{~kg} \mathrm{~N} 2 \mathrm{H} 4$ divided between a pair of 22 inch i.d. diaphragm tanks (Pressure Systems Inc. 80193). Of the $12 \mathrm{~kg}$ of hydrazine in excess of the deorbit burn, half was used for entry RCS. This propulsion system operated over a 2:1 blowdown ratio with an initial pressure of 345 psi. Four thruster modules of three thrusters each ( 2 oriented axially, 1 for roll control) were 60 inches from the vehicle centerline. The $5 \mathrm{lb}$ thrust engines (MR-50) from Rocket Research (now OAC) massed $\sim 0.8 \mathrm{~kg}$ each. Propulsion fluid-component hardware mass would have been $>25 \mathrm{~kg}$ (12 thrusters +2 tanks).

Schurmeier (1975), Soffen (1978), and Kirk et al. (1978) describe the descent sequence, and information from Martin-Marietta (circa 1976) includes mass numbers. After 3 hours of coast, the propulsion system reoriented the vehicle for atmospheric entry at $-300 \mathrm{~km}$ altitude, which included adjustment of angle of attack for aerodynamic lift. Upon entry at $4.6 \mathrm{~km} / \mathrm{s}, \sim 1000 \mathrm{~kg}$ remained (Martin-Marietta, 1976). The attitude control system limitcycled at approximately $0.1 \mathrm{~Hz}$, until it was turned off when deceleration rose to $.05 \mathrm{~g}(\sim 80$ $\mathrm{km}$ altitude). The aerobraking lasted just a few minutes with a peak axial deceleration of 73 $\mathrm{m} / \mathrm{s}^{2}$. At $6 \mathrm{~km}$ altitude and $250 \mathrm{~m} / \mathrm{s}$ terminal velocity, the $16 \mathrm{~m}$ diameter parachute was deployed, leaving about $800 \mathrm{~kg}$. The aeroshell was subsequently jettisoned, whereupon the landing legs were immediately unfolded. The descent was slowed to $60 \mathrm{~m} / \mathrm{s}$ by the parachute in $45 \mathrm{~s}$, leaving the lander ready for powered descent at $<1.5 \mathrm{~km}$ altitude. After the parachute was released, $\sim 656 \mathrm{~kg}$ remained. The terminal descent propulsion system operated for $40 \mathrm{~s}$ (throttle control by computer and radar), consuming $56 \mathrm{~kg}$ hydrazine at $\sim 205 \mathrm{~s}$ Isp, for $\Delta v=180 \mathrm{~m} / \mathrm{s}$. The actual impact velocity was roughly $2 \mathrm{~m} / \mathrm{s}$. A net landed mass of $600 \mathrm{~kg}$ included residual propellant.

The total propellant load in the terminal descent system was $84 \mathrm{~kg}$, for a total $\Delta \mathrm{v}$ capability of $\sim 275 \mathrm{~m} / \mathrm{s}$. This system had three $600 \mathrm{lb}$ (nominal) thrust hydrazine engines speciallydeveloped by RRC. Tank volume was the same as in the deorbit system, for a 2:1 blowdown ratio, starting at $480 \mathrm{psi}$ in this case. The 7:1 throttleable engines delivered maximum thrust levels of $638 \mathrm{lb}, 506 \mathrm{lb}$, and $370 \mathrm{lb}$, at feed pressures of $480 \mathrm{psi}, 360 \mathrm{psi}$, and $240 \mathrm{psi}$, respectively. The ratio of total maximum thrust to vehicle mass at parachute release was therefore $13 \mathrm{~m} / \mathrm{s}^{2}$. The $28 \mathrm{~kg}$ of unused propellant would have left the final tank pressure at $\sim 300 \mathrm{psi}$, for a final maximum thrust of $\sim 440 \mathrm{lb}$ and a vehicle thrust/mass ratio capability of $9.8 \mathrm{~m} / \mathrm{s}^{2}$ at touchdown.

Each retro thruster contained a radial flow catalyst bed feeding 18 nozzles to minimize plume disturbance of Martian soil (Cunningham, 1977). A catalyst heater was included to ensure a smooth start. The terminal descent propulsion system included a pair of hydrazine tanks at $\sim 10 \mathrm{~kg}$ each, 3 landing engines at $7.7 \mathrm{~kg}$ each, and 4 roll thrusters (a pair mounted on each tank) at $0.8 \mathrm{~kg}$ each, for a total propulsion hardware mass of $\sim 50 \mathrm{~kg}$.

It is noteworthy that Viking followed a gravity curve with no lateral maneuvering prior to landing. Additional propulsive $\Delta \mathrm{v}$ would be required for any hovering or lateral maneuvering.

\section{Mars landing options considered previously}

The basic problem was solved circa 1970 (e.g. Harrison \& Slocumb 1969) for the Viking '75 landers. These authors considered the possibility of replacing the parachute with additional propulsive $\Delta \mathrm{v}$. Their study also concluded that a hard landing using an impact absorber would result in a greater spacecraft mass than a soft-landing propulsive system. 
Taylor and Faust (1973) considered a direct entry option for Viking lander hardware on potential follow-on missions. Changes would be required to withstand greater deceleration, and to provide additional aerodynamic lift.

Schappell and Johnson (1973) describe an autonomous real-time surface sensing system for obstacle avoidance during landing (in reference to a possible future mission using Viking hardware).

Carter \& Smith (1989) studied the landing problem in the context of the Mars Rover Sample Return (MRSR) program (cancelled in 1990). They recommended $350 \mathrm{~m} / \mathrm{s}$ of propulsive $\Delta \mathrm{v}$ to permit up to $2.5 \mathrm{~km}$ of crossrange maneuvering after separation from the parachute, whereas their data indicated $250 \mathrm{~m} / \mathrm{s}$ would be required to land without crossrange maneuvering. The parachute could be more heavily loaded than on Viking, given Viking's data return on the Mars atmosphere, as well as plans for a higher altitude engine ignition. The MRSR on the parachute would have had a ballistic coefficient of 20$25 \mathrm{~kg} / \mathrm{m}^{2}$ before releasing the lander at $2 \mathrm{~km}$ above ground level. The ratio of landing thrust to vehicle mass was specified to be 3 times Mars' gravitational acceleration. Carter and Smith explain that the thrust requirement is driven by uncertainty in the final phase of the landing trajectory (velocity \& altitude).

Carter (now at LLNL) advocates the use of a deployable rotor instead of a parachute, if horizontal maneuvering beyond propulsive capability is required. He indicated that deployable rotors are well understood and can be designed for Mars maneuvering descent with far less testing than is required for gliding parachutes. Even the non-maneuvering Viking parachute, for example, required an extensive high altitude qualification test program, undertaken at White Sands (Moog et al 1974).

Recently, Tuckness (1995) revisited the MRSR study effort, with consideration of obstacle-avoiding crossrange capability. The MRSR descent scenario included an aeroshell and parachute, which leaves the vehicle falling at $120 \mathrm{~m} / \mathrm{s}, 1500 \mathrm{~m}$ above the Martian surface. The propulsive $\Delta v$ specified is $350 \mathrm{~m} / \mathrm{s}$, to support obstacle-avoiding crossrange maneuvering of $1-2 \mathrm{~km}$, in addition to vertical deceleration. The ratio of thrust to Mars weight is required to be between 3 and 4 , which is 1.15 to 1.5 thrust/weight on earth.

The Mars '98 lander is roughly 1/3-1/2 the mass of Viking, and it is planned to fly to Mars independently of the same mission's orbiter. The lander will directly enter Mars' atmosphere in its interplanetary cruise configuration, which presents new challenges relative to Viking. Entry RCS propulsion will be provided by the earth-Mars cruise propulsion system, to be jettisoned along with the aeroshell. The terminal thrust requirement is $720 \mathrm{lb}$ (Daub, 1995). Options under consideration include multiple pairs of high pressure Olin MR-133 hydrazine thrusters derived from a Brilliant Pebbles $500 \mathrm{~N}$ thrust axial engine developed for LLNL. Originally intended to be pump-fed above 1000 psi, the thrusters would be pressure fed by a regulated helium system to $600 \mathrm{psi}$ at the valve inlet, for $\sim 60 \mathrm{lb}$ thrust at $\sim 300$ psi chamber pressure. Pulsing, not throttling, would be used to vary the thrust level as required for a soft landing.

A recent NASA JSC study (Sanders, 1995), MISR (Mars In Situ Resource Utilization Sample Return), considers a direct entry and descent vehicle larger than Viking. The large size opened up several options, including the use of four Viking landing engines (monoprop) at $>600 \mathrm{lb}$ each, or three Shuttle primary RCS (biprop) thrusters at $870 \mathrm{lb}$ each. 


\section{Mars surface mobility-propulsive hopping}

Propulsive hopping can be used for discrete changes of the position of a lander. Small rotational or translational adjustments (e.g. to reorient a camera or obtain a stereoscopic view) are readily achievable as demonstrated by Surveyor VI on the moon (Pfund, 1969). Numerous hops shorter than $1 \mathrm{~km}$ can be performed, and the correction of landing position errors up to $100 \mathrm{~km}$ to reach a specific target point is within the realm of possibility. Given the relatively low propulsive $\Delta v$ requirements for Mars landing, it is entirely feasible to include extra capability for at least some short $(<1 \mathrm{~km})$ hops.

One scheme for lander translation is continuous low-altitude hovering with a horizontal velocity (ultimately limited by aerodynamic drag and navigation risk). Hovering time is the ratio of propulsive $\Delta v$ to Mars' surface gravitational acceleration $\left(3.7 \mathrm{~m} / \mathrm{sec}^{2}\right)$. For example, a propulsive $\Delta v$ capability of $1000 \mathrm{~m} / \mathrm{sec}$ could be used to accelerate the vehicle to $100 \mathrm{~m} / \mathrm{sec}$ horizontally and later decelerate it. The remaining $800 \mathrm{~m} / \mathrm{sec}$ of $\Delta \mathrm{v}$ would permit about $200 \mathrm{sec}$ of hovering, during which time the lander would translate $20 \mathrm{~km}$.

Similarly, a $100 \mathrm{~m} / \mathrm{sec} \Delta v$ margin in the landing propulsion system could be apportioned for a $20 \mathrm{sec}$ hover flight with $10 \mathrm{~m} / \mathrm{s}$ horizontal velocity, to translate $200 \mathrm{~m}$. For very short hops (or vehicle rotations), $10 \mathrm{~m} / \mathrm{sec}$ of $\Delta \mathrm{v}$ would provide $2 \mathrm{sec}$ of hovering during which time the vehicle could translate up to 5 meters at $2.5 \mathrm{~m} / \mathrm{sec}$.

A ballistic trajectory would be more efficient, if the risk associated with higher speed is acceptable. If the same $1000 \mathrm{~m} / \mathrm{sec}$ is split into two impulsive maneuvers for starting and stopping, the initial speed would be $354 \mathrm{~m} / \mathrm{sec}$ both vertically and horizontally. Neglecting drag, vertical speed would be reduced to zero in $95 \mathrm{sec}$. Horizontal translation during the $190 \mathrm{sec}$ flight would be $67 \mathrm{~km}$.

Similarly, a $50 \mathrm{~m} / \mathrm{sec}$ velocity vector at 45 degrees on a flat Mars would result in an initial speed of $35 \mathrm{~m} / \mathrm{s}$ vertically and horizontally. Vertical velocity would be reduced to zero in $9.6 \mathrm{sec}$, for a total flight time of $19 \mathrm{sec}$. The horizontal distance travelled would be $670 \mathrm{~m}$, for a total $\Delta v$ of $100 \mathrm{~m} / \mathrm{sec}$.

Assuming the lander is designed for $2 \mathrm{~m} / \mathrm{sec}$ impact capability in both horizontal and vertical directions simultaneously (similar to Viking), a ballistic hop maneuver of this velocity would consume propellant only at the beginning of the hop. At 45 degrees, 2.8 $\mathrm{m} / \mathrm{sec}$ of initial velocity would yield a Mars flight time of $1.5 \mathrm{sec}$ and a hop distance of $3 \mathrm{~m}$. Extra $\Delta v$ for the non-impulsive burn as well as orienting the thrust vector to 45 degrees would be required, so total $\Delta \mathrm{v}$ for the maneuver would be $\sim 5 \mathrm{~m} / \mathrm{s}$. 


\section{Mars sample return-propulsion requirements}

Mars sample return requires higher propulsive performance ( $\Delta \mathrm{v}$ and acceleration) than any previously accomplished deep space maneuver.

Mars' surface to low orbit $\Delta v$ is $3500 \mathrm{~m} / \mathrm{s}$, with a total of $5900 \mathrm{~m} / \mathrm{sec}$ required to establish an earth transfer trajectory. This can be compared to $1700 \mathrm{~m} / \mathrm{sec}$ and $2600 \mathrm{~m} / \mathrm{sec}$ for lunar orbiting and earth return from the moon, respectively. In addition, Mars' surface gravitational acceleration $(.38 \mathrm{~g})$ over twice that of the moon $(.17 \mathrm{~g})$ requires a significantly higher thrust/mass ratio than the Apollo and Soviet Luna return vehicles.

A Mars sample return capsule would also need to have cruise spacecraft capabilities with a 1-year operating lifetime. This includes a long-life propulsion system for mid-course corrections, and final maneuvering for precision entry into earth's atmosphere. An additional lifetime requirement is a $\sim 2.5$ year storage life starting at earth launch.

As Figure 1 shows, leaving Mars requires a propulsive capability near the geometric mean (in both $\Delta \mathrm{v}$ and thrust) between leaving the moon and launching from earth. The Mars return problem would challenge even the best individual stages of existing earth launch vehicles (e.g. Centaur could bring home its own empty weight as payload). However, given the necessarily small scale required for Mars return vehicles within foreseeable funding expectations, a practical Mars return vehicle would benefit from new propulsion technology which delivers launcher performance on a small scale.

One possibility for sample return is Mars orbit rendezvous with an earth return vehicle. Thus, the Mars launcher would only need to reach Mars orbit. Aside from the difficulty and risks of rendezvous (and possible sample transfer), this scenario requires smaller earth launchers (because the mission is broken up into more pieces) and probably less total mass sent from earth to Mars than direct return from Mars' surface.

Science requirements are to return Mars samples from widely disparate locations thousands of km apart (e.g. see National Research Council, 1990). Given the difficulty of surface mobility over these distances, the risks associated with rugged surface features, and finally the risk of recovering high velocity RV's in earth's atmosphere, it may be desirable to send an individual lander and sample return vehicle to each identified sampling location.

Mars sample return options considered previously, including in-situ propellants

Mars sample return propulsion was addressed by Weaver (1974). This trade study considered the use of conventional spacecraft propulsion technology, and found pressurefed (moderate pressure) liquid engine weight to be so high that a two stage solid rocket was proposed.

More recently, Rocketdyne's XLR-132 engine (Aerojet also developed a version) has been under consideration for Mars launchers. This smallest of modern turbopump-fed rocket engines, developed for the MX missile fourth stage, delivers $3750 \mathrm{lb}$ of thrust at $1500 \mathrm{psi}$ chamber pressure using standard storable bipropellants (NTO \& MMH) from low-pressure tanks. The development program culminated in fabrication and testing of two flightweight engines in 1991, but none were produced or flown (Dave Crisalli, Rocketdyne, personal communication). The Mars Rover Sample Return (MRSR) Program (JSC, circa 1990) converged on a pump-fed XLR-132 first stage concept, with a Shuttle primary RCS on the pressure fed second stage. This was found to be lighter than a solid first stage based four STAR 17A motors (Sanders, JSC, private communication). 
A much more futuristic approach is to manufacture propellants on Mars. Bob Zubrin of Lockheed-Martin (Martin Marietta Astronautics, Denver) is perhaps the most ardent activist and has written numerous technical papers on this subject, many of which are oriented towards human presence on Mars.

Two recent papers (Sanders 1995, Zubrin et al 1995) describe work funded by NASA JSC and conducted at JSC and Martin Denver. A Delta II (7925) launch would place nearly $1500 \mathrm{~kg}$ into a trans-Mars trajectory with its STAR 48 upper stage solid motor. Over 1000 $\mathrm{kg}$ is envisioned to be landed mass on Mars. This would include a 2-stage (earth entry capsule is third stage) return vehicle having a mass of $\sim 100 \mathrm{~kg}$ with empty tanks, to be filled with liquid oxygen and methane (possibly propane). Up to $500 \mathrm{~kg}$ of propellants would be made at the rate of $\sim 1 \mathrm{~kg}$ per day (running continuously) from Martian atmospheric $\mathrm{CO}_{2}$, and hydrogen carried from earth having a mass $1 / 12$ that of the propellants to be produced.

The first stage of the Mars launch vehicle would be pump-fed (Sanders, 1995).

The prototype propellant plant at Martin has a working component mass sum of just $21 \mathrm{~kg}$ (Zubrin et al, 1995). Power requirements for the Sabatier process $(\mathrm{CO} 2+\mathrm{H} 2 \rightarrow \mathrm{CH} 4+$ $\mathrm{H} 2 \mathrm{O}$ ) and subsequent water electrolysis and refrigeration (the oxygen but not methane) were measured at $300 \mathrm{~W}$. This would require a RTG (radioisotope thermal generator) or up to $30 \mathrm{~m}^{2}$ of solar cells $\left(100 \mathrm{~W} / \mathrm{m}^{2}\right.$ average power $\left.\mathrm{x} 10 \%\right)$ plus $5000 \mathrm{~W}$-hr of overnight energy storage (e.g. up to $100 \mathrm{~kg}$ of batteries).

Obtaining propellants on Mars certainly makes more sense than carrying them there from earth, and progress to date has been encouraging. It would be unfortunate if hydrogen must be carried from earth, because containers are far heavier than the hydrogen itself, which eliminates most of the 12:1 mass advantage of Mars production. Using the best and latest flight qualified composite tank technology (Hughes HS-601 helium tank made by $\mathrm{SCI}$ ), tank mass would be 8 times that of the hydrogen (operating PV/W $=650 \mathrm{k}$ inch, safety factor $\sim 1.6$ ). In terms of the hydrogen content, it would be equally mass-intensive to carry water from earth. The net gain from Martian propellant production would only be 1.5 times in mass, relative to a more storable propellant that could be lifted from earth.

Cryogenic transportation of hydrogen is highly scale-dependent since boiloff depends on the surface/volume ratio. Huge unpressurized tanks of liquid hydrogen can last for years between earth and Mars, but small quantities require dewars far heavier than the hydrogen itself. An alternative to carrying hydrogen from earth is to use Mars atmospheric water.

Although the hydrogen feedstock source seems to be the most significant unresolved issue, there are other considerations in producing propellants on Mars and using them for sample return. Complexity limits the scale-down potential relative to that of systems with stored propellants. The stoichiometry of the above process yields oxygen and methane at a mass ratio of 2 which has a theoretical vacuum Isp (area ratio 50) of $330 \mathrm{~s}$, rather than 369 at the optimum 3.5 mixture ratio. The Mars launcher tanks would be relatively heavy dewars. All new hardware must be developed for the return propulsion system. Heavily insulated or vacuum jacketed fluid lines would have to be automatically disconnected from the Mars launcher.

An alternative notion advocated by Zubrin (1995) reduces complexity by using Mars' atmospheric $\mathrm{CO} 2$ directly as a rocket oxidizer. Only one quarter of the propellant mass, $\mathrm{B} 2 \mathrm{H} 6$ fuel, would be carried from earth. Its liquid density is less than half that of conventional spacecraft propellants, and its pressure is $\sim 600$ psia under typical earth launch conditions, which would impact mass and volume of the Mars launcher fuel tank. 


\section{Other propulsion requirements for Mars exploration}

From LEO, $3800 \mathrm{~m} / \mathrm{s} \Delta \mathrm{v}$ (a little higher than earth escape) is required for a trans-Mars trajectory. In 1975, Titan-IIIE-Centaur vehicles sent both $3530 \mathrm{~kg}$ (Schmit, 1981) Viking spacecraft on this trajectory. The two-burn Centaur operation included a restart in LEO for trans Mars injection, which incidentally included the use of hydrogen peroxide thrusters to settle the main tanks prior to restart (Richards, 1989). After Centaur separation, the spacecraft mass was approximately $1 / 3$ propellant for Mars orbit insertion (MOI), 1/3 dry orbiter, and $1 / 3$ landing package. The actual landed mass was about half of the package which deorbited, or just $1 / 6$ of the spacecraft mass during its earth-Mars cruise.

The MOI maneuver requires $1100 \mathrm{~m} / \mathrm{sec} \Delta \mathrm{v}$, for the Viking orbits. Viking did not use the most efficient way to reach the Mars surface. This is a key fact when smaller budgets and smaller launchers are considered for Mars exploration. The Mars '96 Pathfinder mission and the Mars '98 Surveyor mission both use landing packages which enter the Mars atmosphere directly from the earth-Mars trajectory, after separating from cruise hardware. Although these currently-funded missions have smaller landers than Viking, JSC and Martin Denver have calculated that a direct lander launched by a Delta II 7925 can be larger than the Viking lander, even though this launcher is much smaller than Viking's Titan-IIIECentaur (see previous section on proposed sample return options).

Aerocapture has been advocated as a lower-mass means to insert a spacecraft into orbit about Mars. This would eliminate the $1100 \mathrm{~m} / \mathrm{s}$ propulsive requirement, but it requires precise navigation relative to the atmosphere, as well as designing for the thermal loads.

It is interesting to note that Mars' atmosphere makes the surface more accessible than that of the moon, from the standpoint of propulsive $\Delta v$ only. There are other reasons to explore Mars (rather than the moon) with the tiniest landers sent by small earth-launch vehicles. Thermal survival is easier in the absence of a fortnight-long lunar night, and of course, Mars' surface is less well known.

As miniaturization of scientific instruments, digital electronics, and propulsion progresses, it may be useful to keep in mind that the surface of Mars is theoretically within one propulsive stage $(-2 \mathrm{~km} / \mathrm{s})$ of geosynchronous transfer orbit (GTO). From the point of view of low earth orbit (LEO), a $362 \mathrm{~kg}$ STAR 27 solid motor (Thiokol) can impart 3830 $\mathrm{m} / \mathrm{s}$ to $140 \mathrm{~kg}$, to send it to Mars. The $500 \mathrm{~kg}$ total package can almost be lifted to LEO by a Pegasus. 


\section{Comments on propulsion technology relevant to Mars missions}

A description of the maneuvering capability of a spacecraft, or of the maneuvering requirement for a particular mission, must always include two key performance parameters. These are the velocity change $(\Delta v)$, and the thrust/mass ratio (acceleration). From a propulsion engineering standpoint, these are respectively related to the propellant carrying capacity and to the thrust delivery capability, of a given mass of propulsion hardware. In Figures 1 and 2, the $\Delta \mathrm{v}$ and initial acceleration are used as the axes of graphs which depict the 2-dimentional continuum of space maneuvering performance. The most difficult maneuvers require both high $\Delta \mathrm{v}$ and high acceleration, whereas it is somewhat easier to obtain either one alone.

Figure 1 graphically presents the propulsive requirements for some space missions, and also includes the maneuvering capabilities of some historical spacecraft and other rocketpropelled vehicles. For example, the Mars terminal descent requirement is in the upper center of the graph, and the Mars to earth maneuver falls near the right boundary. Figure 2 shows the general regions of applicability of different rocket propulsion technologies, plotted on the same axes as Figure 1. The boundaries in Figure 2 cannot be precise, since the fraction of spacecraft mass devoted to the propulsion system varies widely. Also, note that any technology can usually meet any lesser requirement (lower $\Delta \mathrm{v}$ and/or acceleration) relative to its maximum capability. One possible exception is that it is not practical to arbitrarily reduce the thrust level of a solid rocket motor having a given amount of propellant.

Modern spacecraft are designed for orbit maintenance over decade-scale lifetimes, which has biased liquid space propulsion technology toward high propellant carrying capacity and long-life hardware at low acceleration. A very different kind of propulsion capability is available from solid motors, and from liquid systems which have been developed in recent years for missile defense. Most of the latter systems have relatively small propellant fractions, and they operate for short durations at high pressure which permits high acceleration to be achieved. Whereas standard spacecraft technology is expected to be high in thruster weight if adapted for Mars landing, the latter's propulsive requirements are similar to those for missile defense. Although this statement is true regardless of absolute size considerations, the present interest in smaller Mars landers provides an even stronger motivation to utilize defense developments, which have been built on a smaller absolute size scale than spacecraft propulsion. The relative immaturity of the new technology, however, is a significant consideration.

Conventional spacecraft propulsion

Spacecraft typically carry tens to hundreds of kilograms of toxic propellant(s) in tanks having diameters ranging from 12 inches to 48 inches. The largest tanks can contain 30 times their own mass in propellant, but the smallest tanks contain as little as only 5 times their own mass. The tanks are pressurized with inert gas to deliver liquid propellants to thrusters at between 100 and 500 psi. Blowdown systems (typical for monoprop hydrazine) use the ullage gas in the propellant tank, so that pressure falls as the mission proceeds. Regulated systems (typical for bipropellants) use a separate high pressure gas bottle and a regulator to keep propellant tank pressure constant. Most available liquid thrusters are in the range from 0.1 to $100 \mathrm{lb}$ of thrust, with thrust/weight ratios varying from less than 1 for low thrust, up to approximately 20 at the high end. Given that real hardware does not follow ideal scaling laws (constant tankage fractions and thrust/weight), there is a practical lower limit to the size of spacecraft propulsion systems which can be built from conventional components. 
Pressure fed missile defense propulsion

Defense propulsion systems developed over the last decade carried propellant quantities roughly in the 1 to $10 \mathrm{~kg}$ range. Most were designed for multidirectional acceleration and/or high vibration, so their specialized liquid tanks included metal diaphragms or pistons for positive ullage control. Propellants were delivered to thrusters at pressures between 600 and 1500 psi. Tanks used for pressure-fed operation contained fewer than 5 times their own weight in propellants, while thruster output exceeded 1000 times their own weight in some cases. Thrust levels spanned roughly the same range as standard spacecraft thrusters.

\section{Thrust chamber mass}

Very roughly, thrust is the product of chamber pressure and throat area. Although higher chamber pressures require stronger walls, a net weight reduction results from increasing pressure and reducing size for a given thrust level. Long life requirements increase mass, due to the need to tolerate or reduce catalyst degradation and/or erosion. Mass increases with area ratio, since the expansion nozzle must be larger. Thrust chamber valve mass is increased by stringent leakage requirements.

\section{Monopropellant hydrazine thrusters}

A standard long-life $100 \mathrm{lb}$ thruster, the Olin MR-104A, has a thrust/weight ratio of 25 at the top end of its operating pressure range (feed $500 \mathrm{psi}$, chamber $125 \mathrm{psi}$ ). It can run continuously for over a half hour, or deliver a similar total impulse as many separate pulses over many years, with separate cold starts. In contrast, the short life Viking landing thruster $(600 \mathrm{lb})$ developed by Olin demonstrated a thrust/weight ratio of 35 , higher than any long life satellite thruster.

The Olin MR-125 thruster (250 N, $56 \mathrm{lb})$ was developed under contract to LLNL for the high thrust/weight Brilliant Pebbles mission. Four were flown on LLNL's ASTRID pumped propulsion experiment, with modified sea level nozzles (the entire flight record to date). A relatively short life requirement, high pressure (feed $1100 \mathrm{psi}$, chamber $600 \mathrm{psi}$ ), the absence of a catalyst heater, and aggressive valve technology, permit a thrust/weight ratio of 125 (including $.09 \mathrm{~kg}$ valve). Despite the original $~ 1$-minute lifetime requirement, an individual thruster was successfully tested to $1000 \mathrm{sec}$ life, including a single $600 \mathrm{sec}$ burn which consumed $64 \mathrm{~kg}$ of propellant (Brewster, 1994). In addition, a wide range of feed pressures was demonstrated, indicating capability for operation at nominally lower pressures, or in a blowdown system. The MR-125 is appropriate for missions having short operational lifetimes (there is no catalyst heater, so it is not particularly suited to millions of short pulses). This thruster is ideal for landing on Mars, and its larger sibling is under consideration for NASA's Mars '98 lander.

Bipropellant thrusters

A similar comparison can be made for bipropellant thrusters. The Kaiser-Marquardt R-4D $110 \mathrm{lb}$ thruster (originally developed for Apollo) has a thrust/weight ratio of 12 at $220 \mathrm{psi}$ feed pressure and a 164 area ratio. A miniature short-life high pressure ( $850 \mathrm{psi}$ feed) thruster developed by Rocketdyne has the same thrust, at a thrust/weight ratio of 485 (40 times lighter!). Examples herein are merely representations of the technology. Similar thrusters are made by other companies throughout the world.

\section{Thrusters for less toxic liquid propellants}

Hydrogen peroxide monopropellant thrusters were used for reaction control on many U.S. vehicles in the 1950's and 1960's, including manned aircraft (X-15 etc.) and spacecraft (Mercury capsule), as well as for ullage settling on Centaur flights through 1983. The technology was refined at Bell Aerospace (now Atlantic Research), but $\mathrm{H} 2 \mathrm{O} 2$ was replaced in the U.S. by hydrazine which is more stable in long term storage and has a higher 
specific impulse ( $\sim 230$ s vs. $\sim 160$ s). The Russian Soyuz currently uses $\mathrm{H} 2 \mathrm{O} 2$ for reentry RCS.

Bipropellant thrusters using alcohol or hydrocarbon fuels (kerosene or solid polyethylene hybrid) with $\mathrm{H} 2 \mathrm{O} 2$ have been tested over the years. British sounding rockets (Black Knight) and one launcher (Black Arrow) in 1971 used peroxide/kerosene main engines, and the Rocketdyne AR-2 was used extensively on the NF-104 research aircraft. Clapp (1993) briefly reviews some history of H2O2 use. Small biprop thrusters using H2O2 do not seem to have any history of space flight, although there are records of their development (Burtoft, 1965).

Slow decomposition of $\mathrm{H} 2 \mathrm{O} 2$ during storage is seen as a drawback. However, the author notes that the possibility of using the oxygen gas produced for reaction control is synergistic with the need for gas jet RCS on tiny spacecraft. Recently, interest in nontoxic propellants has been growing (e.g. Cort et al 1995 and Sellers 1995). Isp values for nontoxic propellants (assuming 90\% $\mathrm{H} 2 \mathrm{O} 2$ ) in the present work were obtained from Cort (1995), and then conservatively reduced by $5 \%(295 \mathrm{~s} \times .95=280 \mathrm{~s})$ to account for the lack of years of refinement for any newly developed thruster.

Small scale pump-fed engines

Small pump-fed engines are appropriate for Mars sample return missions. Figures 3 and 4 are plots of pump performance versus thrust level. The graphs illustrate the limitation of scaling down turbopumps. Reciprocating pumps are preferred to turbopumps for low thrust levels up to at least $1,000 \mathrm{lb}$. A $100 \mathrm{lb}$ pump fed hydrazine system has been demonstrated in flight (Whitehead et al, 1994), and it seems entirely feasible to implement this concept with other propellants. Development work would be required.

\section{Conventional solid motors}

The typical characteristics of conventional solid rocket motors include a single continuous burn at very high thrust/weight ratios, until all propellant is exhausted. Solid motors have excellent mass fractions, high density, and a specific impulse between those of monopropellant and bipropellant liquids. Solid motors have therefore been proposed for mars launchers (sample return). One interesting advantage of solid propellant is that it need not be kept warm throughout a mission to prevent freezing. Increased complexity is required for stopping and restarting, but there is a history of throttleable or pulse-capable solid rockets, particularly for attitude control (Polaris and Poseidon missiles). Alternatively (and typically in space), attitude control during a solid burn can be accomplished by vehicle spinning, some sort of thrust vector control, or a separate liquid reaction control system. For example, the (lunar) Surveyor of the 1960's used a solid motor for the main deceleration burn, but required a vernier liquid system for reaction control and terminal landing. Mars landing requires mostly terminal maneuvering without a large deceleration burn, so liquid propulsion has traditionally been favored for this task. NASA's Pathfinder hard lander will use a solid retro motor to shed some velocity, and solid propellant gas generators to inflate "air" bags for impact.

Solid missile defense propulsion

Recent advances in solid propulsion for missile defense include a demonstrated capability for precise maneuvering by pulsing (hover tests), and moreover this has occurred on a small $(\sim 10 \mathrm{~kg})$ scale. In contrast to the defense liquid systems, the advance here is controllability, rather than large reductions in inert weight. Recent development includes work at Aerojet, Allied Signal (Garrett), Thiokol, and Chemical Systems Division (United Technologies), but there is virtually no space flight history. The propellant grain(s) must be tailored to the mission, and propellant is wasted by pulsing since combustion continues and gas must be expended effectively nonpropulsively. Thiokol's LEAP propulsion 
system switched thrust between opposite directions, on each of several axes. It was hovertested with a special grain very different from the mission design. Pulsed solids have an effective Isp reduction by approximately the ratio of average required thrust to maximum required thrust. Grain mass can be directly calculated as the product of burn time and maximum thrust divided by Isp, since the relatively constant burn rate must support maximum thrust. Delivered $\Delta \mathrm{v}$ depends not only on the average thrust, but on its distribution over time.

Hybrid rockets

Hybrids typically combust a solid fuel grain with a liquid oxidizer. The oxidizer can be valved off, so they are easier to control than solids. Inherent safety appears to be an advantage, because the fuel and oxidizer are not pre-mixed (as in solids or monoprops) and do not readily mix in accidents (as liquids can). Hybrids are currently the subject of numerous R\&D efforts, particularly at universities. As noted above, low-toxicity oxidizers are of interest. There is no space flight history for hybrid rockets.

Volume requirements

The volume occupied by a rocket propulsion system does not explicitly appear in performance calculations, but it can be of key importance when designing mission hardware (e.g. to fit inside a Mars lander aeroshell). Generally, volume varies inversely with propellant density, which favors solids. In addition to having a lower propellant density, liquid systems flown in space to date carry significant quantities of stored gas. Advanced systems which use pumps to deliver propellant either to engines or to a tankpressurizing gas generator, can operate with negligible stored gas volumes.

Ground servicing at launch site

The need for specialized ground servicing equipment (GSE) and procedures is a significant practical factor which should always be considered when comparing different propulsion technologies for a mission. For example, solid motors require minimal launch site servicing, but have the potential for explosion and detonation. Purohit et al. (1992) have written a detailed description of ground operations for conventional liquid spacecraft systems. Conventional toxic liquid propellants require significant GSE including SCAPE (self contained atmospheric protection ensemble), becuase human exposure to the vapors is intolerable. SCAPE is not perceived to be necessary for handling $\mathrm{H} 2 \mathrm{O} 2$, and it may even be acceptable to pour the liquid instead of always confining it within tubes for filling or contingency draining. However, the lower chemical stability of $\mathrm{H} 2 \mathrm{O} 2$ relative to conventional space propellants may make some aspects of ground handling more difficult. The relative safety of $\mathrm{H} 2 \mathrm{O} 2$ is controversial, and there will doubtlessly be a learning curve if this propellant comes into common use again at U.S. launch ranges. Aside from personnel safety, the concerns of environmental impact in the event of propellant spills are always increasing. The ultimate result of $\mathrm{H} 2 \mathrm{O} 2$ spills (releasing water and oxygen into the environment) is relatively benign. 


\section{Propulsion options for a $100 \mathrm{~kg}$ Mars lander}

A number of options have been generated, as listed and described below. They are compared graphically in Figures 5 and 6. Figure 5 shows only monopropellant hydrazine options, including the Viking lander case scaled down. Figure 6 presents systems using conventional bipropellants, and nontoxic propellants. Solid propellant designs are considered but not plotted due to the difficulty of making a fair comparison. In particular, only the masses of "wet" components are included for liquid system options, so any required structure would be associated with the rest of the spacecraft. The assumptions are:

Thrust range for $10-15 \mathrm{~m} / \mathrm{sec}^{2}$ deceleration: Landing mass (w/ propellant after 'chute jettison): Propellant mass for $\Delta v=350 \mathrm{~m} / \mathrm{s}$ : monopropellant hydrazine (Isp $=230 \mathrm{~s}$ ) standard bipropellants (Isp $=310 \mathrm{~s}$ )

nontoxic monopropellant (Isp $=160 \mathrm{~s}$ ) Total RCS impulse: nontoxic bipropellants (Isp $=280 \mathrm{~s}$ ) pulse-capable solid propellant (Isp=253 s)
$1000-1500 \mathrm{~N}(225-337 \mathrm{lb})$

$100 \mathrm{~kg}$

\section{$15 \mathrm{~kg}$ (15 liters)}

$11 \mathrm{~kg}(6.9 \mathrm{~kg} \mathrm{~N} 2 \mathrm{O} 4+4.1 \mathrm{~kg} \mathrm{MMH})$

(4.7 liters each)

$20 \mathrm{~kg}$ of $90 \% \mathrm{H} 2 \mathrm{O} 2$ (14.5 liters) $12 \mathrm{~kg}(10.690 \% \mathrm{H} 2 \mathrm{O} 2+1.4 \mathrm{HC})$ $>13 \mathrm{~kg}$ (Thiokol LEAP formulation)

$1 \%$ of maneuvering impulse

Note that a detailed analysis of reaction control requirements for attitude control is beyond the scope of the present study. In general, such requirements are determined by the need to overcome maneuvering thrust misalignment and aerodynamic torques, the need to maintain angular positions within acceptable limits, and the need to accomplish required rotational maneuvers sufficiently quickly. In the above list, the RCS requirement is arbitrarily set to a small number for roll control, since pitch and yaw can be controlled by throttling or pulsing multiple descent engines.

\section{System options considered and described below}

1. Viking terminal descent propulsion masses scaled down by factor of 5.6

2. standard spacecraft hydrazine technology with off-the-shelf flight-proven components

3. high pressure blowdown hydrazine system using some missile defense components

4. moderately high pressure regulated hydrazine, some missile defense components

5. warm gas pressurized hydrazine at moderate to high pressure

6. high pressure pump-fed hydrazine system derived from LLNL ASTRID

7. high pressure cold-gas-driven pump-fed hydrazine with cold gas RCS

8. standard spacecraft bipropellant technology with off-the-shelf flight-proven components

9. high pressure regulated biprop system using missile defense components

10. high pressure pump-fed conventional biprops (extended ASTRID technology)

11. warm gas pressurized nontoxic monopropellant hydrogen peroxide

12. high pressure pump-fed nontoxic monopropellant hydrogen peroxide

13. warm gas pressurized nontoxic bipropellant system using new components

14. high pressure pump-fed nontoxic bipropellant system using new components

15. pulse-capable solid derived from miniature missile defense technology 
1. Viking terminal descent propulsion masses scaled down by factor of 5.6

Viking's $84 \mathrm{~kg}$ of hydrazine is scaled to the $15 \mathrm{~kg}$ required for a $100 \mathrm{~kg}$ lander.

\begin{tabular}{lllll} 
& & & & \\
component & manufacturer & part $\mathrm{nr}$ & quantity $\times$ mass & $\begin{array}{l}\text { scaled } \\
\text { total mass, } \mathrm{kg}\end{array}$ \\
\hline 2 spherical tanks & PSI & & $2 \times \sim 10 \mathrm{~kg}$ & 3.6 \\
600 lb main thruster & Olin & & $3 \times 7.7$ & 4.1 \\
$5 \mathrm{lb}$ roll thruster & Olin & MR-50 & $4 \times 0.8$ & 0.6 \\
plumbing, iso valves, fill valves & misc. & (estimate) & 1.0 \\
\multicolumn{2}{l}{ Total mass of key components: } & & & 9.3
\end{tabular}

This scaling is theoretical only, as smaller conventional components tend to have a greater mass than is expected from linear scaling.

2. Standard spacecraft hydrazine technology with off-the-shelf flight-proven components The smallest known hydrazine systems (not all have flown) which use standard, flight proven components are listed below.

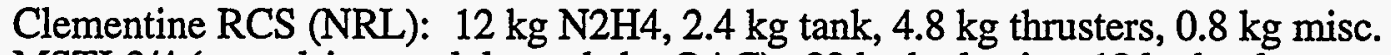
MSTI-3/4 (propulsion module made by OAC): $22 \mathrm{~kg}$ hydrazine, $18 \mathrm{~kg}$ hardware ACE (OAC propulsion module): $200 \mathrm{~kg}$ hydrazine, $\sim 25 \mathrm{~kg}$ hardware

For Mars landing, a standard hydrazine system could operate with a low blowdown ratio of 2:1 to minimize thrust reduction as Viking did. The tank chosen below operates at $350 \mathrm{psi}$ maximum, so the MR-104A thrusters would deliver 400-275 $\mathrm{N}$ each over the blowdown. If tank pressure could be increased to $500 \mathrm{psi}, 3$ main thrusters would be sufficient.

\begin{tabular}{lllcl} 
component & manufacturer & part nr & quantity x mass & total mass, kg \\
\hline 37 1 diaphragm tank, $\varnothing 17$ in & PSI & $80253-1$ & $1 \times 3.9$ & 3.9 \\
$100 \mathrm{lb}$ main thruster & Olin & MR-104A & $4 \times 1.9$ & 7.5 \\
1 lb roll thruster & Olin & MR-111C & $4 \times .33$ & 1.3 \\
plumbing, iso valves, fill valves & misc. & & 1.0
\end{tabular}

Total mass of key components:

Issues: $\quad$ 1. response time of standard spacecraft thrusters, re precise maneuvering

2. separate pitch/yaw thrusters needed for entry RCS?

3. main thrusters are large, 18 inch long, 6 inches diameter at the exit

If tank pressure is held constant, a smaller, lighter, diaphragm tank such as PSI 80342-1 would be applicable. It is rated for $480 \mathrm{psi}$ and $14.7 \mathrm{~kg}$ of hydrazine, with a mass of 2.7 $\mathrm{kg}$. Total internal volume is 15 liters. One of the thrusters could be eliminated, and a pressurant tank and regulator would need to be added for a standard regulated system, resulting in a $1-2 \mathrm{~kg}$ net mass reduction at the cost of greater complexity than the blowdown system.

Another alternative tank is lighter by virtue of not being designed for microgravity operation. This 18 liter titanium tank made by PSI (80148-1) for the 777 has a mass of 1.6 $\mathrm{kg}$ and operates at up to $585 \mathrm{psi}$. This tank is also considered for other options below which use lightweight MR-125 thrusters. 


\section{High pressure blowdown hydrazine using some missile defense components}

This option uses existing tank and thruster designs. High tank mass, exacerbated by the metal diaphragm's residual propellant, is a consequence of the very limited selection of existing tanks capable of a high starting pressure above 1000 psi. The blowdown ratio is 2.7, from 1200 down to $450 \mathrm{psi}$, considering residual propellant volume. Twelve MR-125 thrusters deliver $3000 \mathrm{~N}$ down to $1100 \mathrm{~N}$. The 12 main engines are appropriately angled so they provide roll control. This is a very simple system and is certainly better than using standard spacecraft thrusters.

\begin{tabular}{lllcl} 
component & manufacturer & part $\mathrm{nr}$ & quantity $\times$ mass & total mass, $\mathrm{kg}$ \\
\hline 4 l diaphragm tank, $\varnothing 8.2$ in & Arde & D4187-3 & $6 \times 1.25$ & 7.5 \\
residual hydrazine in tanks & & & $6 \times .31$ & 1.9 \\
56 lb lightweight thruster & Olin & MR-125 & $12 \times .2$ & 2.4 \\
plumbing, iso valves, fill valves & misc. & & 1.0
\end{tabular}

Total mass of key components:

Issues: $\quad$ 1. tank safety factor (1.5) is lower than (2) typically found on spacecraft, which is likely to be an issue with range safety, especially considering the high pressure and hydrazine toxicity.

2. blowdown tanks require a lot of volume within the lander

3. multiplicity of thrusters requires extra mounting bracket mass

The Arde D4187-3, 8.2 inch diameter cryo-301 diaphragm tank has an operating pressure of $1270 \mathrm{psi}$, and an expelled volume of 3.5 liters. This tank has a low safety factor, probably not good for blowdown operation which would require it to be pressurized at launch. Six tanks would cost $\$ 200 \mathrm{~K}$. Atlantic Research diaphragm tanks which are comparable are of aluminum, and have operating pressures below 900 psi.

An alternative tank without diaphragms is PSI part number 80148-1 (777 tank), which is limited to half the above operating pressure (585 psi), so a larger initial ullage volume is required. Four such tanks containing $15 \mathrm{~kg}$ hydrazine in a total of 72 liters would blow down from $575 \mathrm{psi}$ (safety factor 2.3 ) to $450 \mathrm{psi}$. Thrust would not vary much, and total tank mass would be reduced to $6.4 \mathrm{~kg}$. However, the four 12.7 inch diameter tanks would be difficult to package.

This high pressure blowdown hydrazine system remains the simplest in concept and takes advantage of the lightweight MR-125 thrusters. It is therefore attractive to enhance this option with custom tank work. Ideally, a pair of 777 tanks could be qualified to operate at $780 \mathrm{psi}$ (hardware unchanged, safety factor reduced to 1.7). The resulting blowdown pressure range would be 780-450 psi, and total tank weight would be just $3.2 \mathrm{~kg}$ (similar to the blowdown tank mass for option 1). However, note that blowdown tanks must be at their maximum operating pressure during launch, so the safety factor is a range safety issue.

\section{4. moderately high pressure regulated hydrazine, some missile defense components}

Lockheed-Martin is planning to use this general approach for the larger scale Mars '98 lander. Given that the MR-125 thrusters operate over a wide pressure range, there is significant freedom in choosing the regulated system pressure. The optimization presented below indicates that the pressure should be significantly below the thruster design pressure 
in order to avoid excessive tank mass. Feed pressure is near optimum at $450 \mathrm{psi}$, as determined by an existing helium tank design (developed for Brilliant Pebbles). Both tanks have excellent safety factors, near 3. As with the high pressure blowdown hydrazine option, the main thrusters are assumed to be appropriately angled and pulse-modulated for 3-axis reaction control. The regulator and miscellaneous plumbing parts are assumed to be based on moderately aggressive missile defense propulsion technology

\begin{tabular}{lllcl} 
component & manufacturer & part nr & quantity x mass & total mass, $\mathrm{kg}$ \\
\hline 18 I tank, 12.7 inch dia & PSI & $80148-1$ & $1 \times 1.6 \mathrm{~kg}$ & 1.6 \\
56 lb lightweight thruster & Olin & MR-125 & $12 \times 0.2$ & 2.4 \\
Helium tank & SCI & 5130 & $1 \times 0.7$ & 0.7 \\
regulator & estimate & & $1 \times 0.1$ & 0.1 \\
plumbing, iso valves, fill valves & misc. & & 1.0
\end{tabular}

Total mass of key components: $\quad$. $\quad 5.8$

Issues: $\quad$ 1. Attitude control should be carefully thought through

2. propellant tank not designed for microgravity

Elastomer diaphragm tanks having approximately the required volume mass $\geq 2.2 \mathrm{~kg}$.

This option is the lightest hydrazine system considered so far, at the cost of slightly greater complexity and risk (regulator leakage) than the blowdown system. A pyro valve between the helium tank and regulator would not be opened until arrival at Mars.

For pressure optimization, consider the effect of pressure on hardware mass for this regulated system. Higher pressures require fewer thrusters but heavier tank walls, while lower pressures require more thrusters but thinner tank walls. The number of MR-125 thrusters needed is given by ratio of required thrust to feed pressure, relative to that of a single thruster. Multiplying by the unit mass (assume $0.2 \mathrm{~kg}$ including valve) yields the total engine mass.

Total thruster mass $=\frac{0.2 \mathrm{~kg} \text { mass } \times 7.5 \mathrm{MPa} \text { feed pressure }}{250 \mathrm{~N} \text { thrust }} \times \frac{\text { required thrust }}{\text { actual feed pressure }}$

For $1000 \mathrm{~N}(225 \mathrm{lb})$ thrust, Total thruster mass $(\mathrm{kg})=\frac{6}{\text { actual feed pressure (MPa) }}$

An equation for tank mass (both gas and liquid) as a function of pressure can be based on typical small spacecraft tanks, which have about $10 \%$ of the mass of the hydrazine when operating at $2 \mathrm{MPa}(300 \mathrm{psi})$. Thus, for $15 \mathrm{~kg}$ hydrazine,

Tank mass $(\mathrm{kg})=.75 \times$ actual tank pressure $(\mathrm{MPa})$.

Thus, we seek to minimize $.75 p+6 / p$. The derivative with respect to $p$ is $.75-6 / p^{2}$.

We expect a minimum mass when the derivative is zero, which occurs at $p=2.8 \mathrm{MPa}$, or 410 psi. This design point would have $2.1 \mathrm{~kg}$ of tankage and 10.5 thrusters for an equal mass. The actual design above is based on existing tank availability. 
5. warm gas pressurized hydrazine at moderate to high pressure

This option uses a relatively low-performance (but tiny) pump to push a percent or so of the propellant through a gas generator and back into the tank. This eliminates the helium tank from the moderate pressure regulated hydrazine system, which tends to favor higher system pressure and fewer thrusters. Operating pressure here is $585 \mathrm{psi}$, the limit of an existing tank. Pressure can be much lower prior to and through earth launch, to enhance pad safety.

\begin{tabular}{lllcl} 
component & manufacturer & part nr & quantity x mass & total mass, $\mathrm{kg}$ \\
\hline 18 l tank, 12.7 inch dia & PSI & $80148-1$ & $1 \times 1.6 \mathrm{~kg}$ & 1.6 \\
$56 \mathrm{lb}$ lightweight thruster & Olin & MR-125 & $8 \times 0.2$ & 1.6 \\
pump & estimate & & $1 \times 0.1$ & 0.1 \\
gas generator & estimate & & $1 \times 0.1$ & 0.1 \\
plumbing, iso valves, fill valves & misc. & & 1.0
\end{tabular}

Total mass of key components:

Issues: $\quad$ 1. Not fully developed, concept tested with heavyweight hardware 2. chosen propellant tank not designed for microgravity

Simpkin et al (1988) describe heavyweight tests of this concept performed at Atlantic Research Corp. using a gas driven intensifier (GDI) pump developed at Rocket Research. This work included demonstrating warm gas expulsion from aluminum metal diaphragm tanks, while maintaining acceptable tank wall temperatures. LLNL experience with ASTRID also indicates that it is very easy to lose heat from warm gas on the way to the tank.

There are several options and facts to consider here. A metal diaphragm tank would reduce concerns over liquid decomposition by warm gas (or catalyst particles) entering the tank. For long operating lifetimes, there would be concern with ammonia dissolving in the propellant and poisoning the catalyst, but this doesn't matter for a short mission when the catalyst stays hot. This type of system can use warm gas RCS jets (800F to $1200 \mathrm{~F}$ ), as originally conceived for the missile defense application. LLNL and Olin experience from 1988-1994 is directly applicable to lightweighting the pump and gas generator to the numbers shown above.

This is a very lightweight system, appropriate for a short life at high thrust and low $\Delta \mathrm{v}$. It hasn't been flown before because this type of liquid propulsion system requirement is extremely rare. Any project which intends to fly this system will need to concern itself with objections based on possible thermal problems. When there is doubt, thermal calculations will be interpreted to to mean that the hydrazine will overheat and explode, because no one wants to have an "incident" with toxic propellants in their test lab. Since risky development work is required to build a flightweight system, it may be better to implement it with nontoxic propellants.

\section{6. high pressure pump-fed hydrazine system derived from LLNL ASTRID}

Here, tank pressure is not an issue in selecting an optimum thruster feed pressure. The $1000 \mathrm{~N}$ of thrust required can be obtained from four MR-125 thrusters operating at their 
maximum feed pressure ( $1100 \mathrm{psi})$. It is possible to obtain 3-axis attitude control with 4 appropriately angled thrusters. The system below is essentially an ASTRID with the same tank volume and a slightly greater thrust level, but with a much greater non-propulsion mass. ASTRID's long cylindrical tank massed $0.7 \mathrm{~kg}$ and burst at $450 \mathrm{psi}$. This would be replaced by a custom spherical tank having half the mass and approximately the same burst pressure, for a safety factor greater than 4 .

\begin{tabular}{lllcl} 
component & manufacturer & part nr & quantity x mass & total mass, $\mathrm{kg}$ \\
\hline 15 l tank, 12. inch dia & custom & & $1 \times 0.5 \mathrm{~kg}$ & 0.5 \\
56 lb lightweight thruster & Olin & MR-125 & $4 \times 0.2$ & 0.8 \\
high performance piston pumps (modified ASTRID) & $1 \times 0.5$ & 0.5 \\
gas generator & estimate & & $2 \times 0.15$ & 0.3 \\
plumbing, iso valves, fill valves & misc. & & 1.0
\end{tabular}

Total mass of key components:

Issues: $\quad$ 1. tank weight savings is minimal for this low $\Delta \mathrm{v}$ system

2. no low pressure microgravity tanks exist

3. System complexity requires full-up terrestrial system test

4. Warm gas jet RCS may need to be added

A later section provides a detailed discussion of ASTRID technology and improvements that have been identified over the past year. Several development issues remain if the technology is to be adapted for a long storage period on the way to Mars. Development testing of this complex unusual system is costly, largely due to propellant toxicity. No one has flown a small lightweight hydrazine tank specifically designed to take advantage of the low pressure. The ASTRD tank operated at 50 psi, yet had a burst pressure above 400 . Note that the ASTRID flight hardware was never tested in any rocket company laboratory. The ASTRID tank, even with its pressure safety factor of $>4$, was considered by Olin engineers and test lab personnel to be a potentially dangerous lightweight tank. ASTRID's .008 inch tank wall thickness is also entirely incompatible with standard range safety thinking (must assume metal has a .020 inch flaw size for fracture mechanics analysis). The fear of thin tanks must be related to propellant toxicity, because launch vehicles themselves have tank walls as thin as .010 inches for 10 foot tank diameters (Centaur).

\section{7. high pressure cold-gas-driven pump-fed hydrazine}

Pressure optimization is a trade between number of thrusters and the helium tank. Propellant tank mass is irrelevant, so pressure is higher than the moderately high pressure regulated hydrazine system. The low-pressure tank and thrusters have the same mass as the real pump-fed system. The pump mass is reduced for reasons given below. The quantity of inert gas is the same as for a regulated system at the same pressure (1150 psi).

\begin{tabular}{llcll} 
& manufacturer & part nr & quantity x mass & total mass, $\mathrm{kg}$ \\
\hline 15 l tank, 12. inch dia & custom & & $1 \times 0.5 \mathrm{~kg}$ & 0.5 \\
56 lb lightweight thruster & Olin & MR-125 & $4 \times 0.2$ & 0.8 \\
high performance piston pumps (modified & ASTRID) & $1 \times 0.3$ & 0.3 \\
helium vessel & SCI & 5130 & $2 \times 0.7$ & 1.4 \\
regulator & & $1 \times 0.3$ & 0.3 \\
plumbing, iso valves, fill valves & misc. & & 1.0 \\
Total mass of key components: & & & 4.3
\end{tabular}


Issues: $\quad$ 1. helium tank and pumps results in high volume requirement

2. RCS jets, if needed, would result in heavier gas vessel

This type of system has the disadvantages of both pump-fed (pump mass, complexity, and risk) and pressure fed systems (stored inert gas hazard, tank mass, high press regulator risk). It is included here for completeness, since it has some advantages in implementation which are worth noting. A cold inert gas driven pump would be made of aluminum, with elastomer seals, and no boost ratio would be required. The tank pressurization regulator and any RCS jets would not be required to operate hot. Tank pressure could be low, and significant variation would be tolerable. The only advantage is low tank pressure, which may reduce the cost and mass of a custom tank (re range safety). Propellant isolation may be done with passive burst disks, as tank pressure would not be required to fill the pumps to initiate operation (as in option 6).

This technology was implemented for a Brilliant Pebbles flight experiment, which failed for unrelated reasons. The primary reason for choosing this scheme was the desire to fly a pumped system several years before the real pump was ready. Performance did not receive high priority, and aversion to perceived risk resulted in heavy tanks at $>100$ psi rather than lightweight tanks at 50 psi.

A variation could halve helium tank mass by heating the gas on the thrust chambers.

\section{Standard spacecraft bipropellant technology with off-the-shelf flight-proven components}

A standard biprop system could use three Kaiser-Marquardt R-4D engines at 220 psia feed pressure and Isp $=311 \mathrm{sec}$. Thruster hardware weight actually overcomes the advantage of using biprops for higher Isp!

\begin{tabular}{lllcl} 
component & manufacturer & part $\mathrm{nr}$ & quantity $\times$ mass & total mass, $\mathrm{kg}$ \\
\hline 6.5 l metal diaphragm tank & Atlantic Res. & & $2 \times 1.5$ & 3.0 \\
100 lb main thruster & K-Marquardt & $\mathrm{R}-4 \mathrm{D}$ & $3 \times 3.75$ & 11.3 \\
1 lb roll thruster & K-Marquardt & $\mathrm{R}-2$ & $4 \times .43$ & 1.7 \\
Helium tank & SCI & 462 & $1 \times 0.5$ & 0.5 \\
regulator & estimate & & $1 \times 0.3$ & 0.3 \\
plumbing, iso valves, fill valves & misc. & & 2.0
\end{tabular}

Total mass of key components:

18.8

Issues: $\quad$ 1. main thrusters are large, 22 inch long, 11 inch diameter at exit

2. heavy thrusters are designed for Isp and life on large spacecraft, not intended for high thrust/weight small spacecraft

3. SCI helium tank has probably not flown (re range safety)

4. biprop contamination of Mars landing site

The R-4D thruster was developed for Apollo, and 800 were produced for that program. Possible alternatives include the Aerojet AJ10-221 ( $490 \mathrm{~N}$ thrust, $4.5 \mathrm{~kg}$ mass) as proposed for Cassini, and the MBB/DASA $400 \mathrm{~N}$ engine $(2.7 \mathrm{~kg})$, used on Galileo.

Tank heritage is from missile defense, and it has flown on the BMDO MSTI 2 satellite. Standard "spacecraft" tanks of the required small size are made for hydrazine, so their elastomeric diaphragms are not compatible with N2O4. For example, PSI part nr 80222-1 has the same 9.5 inch diameter as the above tank, and its mass is slightly less at $1.3 \mathrm{~kg}$. If 
custom tank work is acceptable, the diaphragm could be eliminated from the Atlantic Research tank to reduce mass.

Bipropellant attitude control thrusters as baselined above are used commonly on communications satellites, but are rarely found on exploration spacecraft, even if they use bipropellants for maneuvering. As examples, biprop attitude control is found on Galileo but separate attitude control systems are found on Lunar Orbiter, Viking Orbiter, Mars Observer, Cassini, Clementine, and NEAR. Cold gas and monopropellant hydrazine have cleaner plumes than biprops, and are chosen to avoid contamination of science instruments. This may or may not be an issue for Mars landing.

If cold gas attitude control is alternatively used, $0.7 \mathrm{~kg}$ of nitrogen would satisfy the $1 \%$ impulse requirement, in which case N2 would replace the helium pressurant and two more of the above pressurant tanks would be added. Cold gas jets are very lightweight, so this would result in a net mass saving, but there is the risk of leakage and not having enough RCS propellant. The high pressure regulated biprop option below uses nitrogen RCS.

An alternative design approach is to use hydrazine (not MMH) as the fuel, which permits the use of monoprop attitude thrusters and avoids carbon contamination of the landing site. This bipropellant pair (N2H4 and N2O4 was used on the Kaiser-Marquardt LEAP and was recently adopted by Aerojet for the Near Earth Asteroid Rendezvous (NEAR) spacecraft. Aerojet used a Royal Ordnance thruster (LEROS-1) designed for hydrazine fuel (the R-4D has also been run on hydrazine but no one buys it for that purpose due to lack of flight heritage). It is similar in thrust level to the Marquardt R-4D, but its mass is almost twice as high at $6.4 \mathrm{~kg}$. The NEAR design may have been driven by cost (i.e. avoid a completely separate monoprop system for attitude control) rather than mass.

\section{9. high pressure regulated biprop system using missile defense components}

This concept was considered by Bryant et al (1994) with an emphasis on lunar landing, but it is much more applicable to Mars landing due to the $\Delta v$ limitations inherent to heavy, high pressure tanks. A $485 \mathrm{~N}(109 \mathrm{lb})$ thruster developed by Rocketdyne has an earth weight of only $1 \mathrm{~N}$. Feed pressure is $\sim 850 \mathrm{psi}$.

\begin{tabular}{|c|c|c|c|c|}
\hline component & manufacturer & part nr & quantity $x$ mass & total mass, $\mathrm{kg}$ \\
\hline $1.441, \varnothing 6$ in diaphragm tank & Arde & $\mathrm{D} 4272$ & $8 \times 0.44 \mathrm{~kg}$ & 3.5 \\
\hline $109 \mathrm{lb}$ lightweight thruster & Rocketdyne & & $3 \times 0.1 \mathrm{~kg}$ & 0.3 \\
\hline N2 pressurant \& RCS gas & & & $0.8+0.7 \mathrm{~kg}$ & 1.5 \\
\hline 10,000 psi nitrogen tank & & 5046 & $2 \times .55$ & 1.1 \\
\hline $\begin{array}{l}1 \mathrm{lb} \text { gas jets for roll } \\
\text { regulator }\end{array}$ & $\begin{array}{l}\text { Moog, Parker } \\
\text { estimate }\end{array}$ & & $\begin{array}{l}4 \times .025 \\
1 \times 0.3\end{array}$ & $\begin{array}{l}0.1 \\
0.3\end{array}$ \\
\hline plumbing, iso valves, fill va & & misc. & & 2.0 \\
\hline
\end{tabular}

Total mass of key components:

Issues: $\quad$ 1. range safety of high pressure tanks at low safety factor

N2 tank designed for TRW DSAT, safety factor 1.5

2. components not flown in space before

3. any gas leakage is critical

4. very short for lightweight biprop thruster

5. biprop contamination of landing site 
This option may benefit from a custom tank design. The ARC tank used in the standard biprop system is appropriately sized, but rated to only $650 \mathrm{psi}$.

An alternative (high) pressure-fed biprop missile defense technology is the Advanced Liquid Axial Stage, ALAS. It was considered for Mars landing by a NASA Ames study in 1993. The primary advantage would be its specific impulse above $340 \mathrm{~s}$. Less than $10 \mathrm{~kg}$ of propellant would be needed for a $100 \mathrm{~kg}$ vehicle. Engine thrust is in the $1000-2000 \mathrm{~N}$ range, as required. A drawback of ALAS technology is its oxidizer, $\mathrm{ClF}_{5}$, which is perceived to be unusually hazardous. Another issue is the state of readiness; ALAS was never hover-tested or flown as other missile defense propulsion technologies were.

\section{High pressure pump-fed conventional biprops (extended ASTRID technology)}

This system combines the potentially-lightest hardware approach with a high Isp propellant combination. The fuel is hydrazine, which can be decomposed to drive pumps and pressurize tanks to their 50 psi operating pressure. The oxidizer requires a nonexistent low pressure metal diaphragm tank, for diaphragm-propellant compatibility, as well as to permit oxidizer tank pressurization with decomposed hydrazine. The large number of existing small thrusters is consistent with angling them for RCS, as was assumed for the high pressure monoprop designs.

\begin{tabular}{lllcl} 
component & manufacturer & part $\mathrm{nr}$ & quantity $\times$ mass & total mass, $\mathrm{kg}$ \\
\hline 50 psi, 5 1 diaphragm tanks & custom & & $2 \times 0.2 \mathrm{~kg}$ & 0.4 \\
35 lb $(150 \mathrm{~N})$ thrusters & K-Marquardt & $\mathrm{R}-46$ & $8 \times 0.1$ & 0.8 \\
high performance pumps & custom & & $1 \times 0.5$ & 0.5 \\
gas generator & & $2 \times 0.15$ & 0.3 \\
plumbing, iso valves, fill valves, reg. & misc & & 1.0
\end{tabular}

Total mass of key components:

Issues: $\quad$ 1. Most of the hardware doesn't exist

Today, this technology is immature. It would require a dedicated effort at a high cost to develop. A proof of principle test was conducted by Kaiser-Marquardt under contract to LLNL in May 1994. LLNL pumps were driven by LEAP hydrazine gas generators. Both the pumps and the test were costly, largely due to propellant toxicity. A special metal bellows design was used instead of piston seals in the oxidizer pump to prevent contact between N2O 4 and decomposed hydrazine. The Apollo-vintage test facility carried high operating overhead related to complexity and propellant toxicity. For example, the test could not be conducted under atmospheric conditions because the vacuum system was the only option for disposing of the toxic gases. Another significant issue is the high vapor pressure of $\mathrm{N} 2 \mathrm{O} 4$ (1 atmosphere at $70 \mathrm{~F}$ ).

\section{Warm gas pressurized nontoxic monopropellant hydrogen peroxide}

None of the components presently exist. A 17 liter ( $r=16 \mathrm{~cm}, 6.3$ in) spherical tank can be made from stainless steel sheet, cold-rolled for strength (and perhaps coated with polyethylene) before forming hemispheres. At a strength of $100 \mathrm{ksi}$ (half that of Atlas \& Centaur tanks), a 1000 psi burst pressure requires a wall thickness of $1 / 32$ inch. 


\begin{tabular}{lllcl} 
component & manufacturer & part nr & quantity $\times$ mass & total mass, $\mathrm{kg}$ \\
\hline 171 tank, 12.6 inch dia & custom & & $1 \times 2.2 \mathrm{~kg}$ & 2.2 \\
$350 \mathrm{~N}$ thruster & custom & estimate & $3 \times 0.5$ & 1.5 \\
pump & estimate & & $1 \times 0.1$ & 0.1 \\
gas generator & estimate & & $1 \times 0.1$ & 0.1 \\
plumbing, iso valves, fill valves & misc. & & 1.0
\end{tabular}

Total mass of key components:

Issues: $\quad$ 1. slow decomposition may require oxygen venting during 1-year cruise

2. low Isp when used as a monopropellant

3. thruster development

This seems to be the most readily implemented option for all-new propulsion technology that uses less toxic propellant(s), and it is lighter for the $100 \mathrm{~kg}$ lander than conventional spacecraft propulsion using off-the-shelf parts. The cost of developing all new hardware is less than the cost of developing hardware for highly toxic propellants. Note that inert-gas pressurized $\mathrm{H} 2 \mathrm{O} 2$ was not considered in this study because a significant engineering advance is appropriate to compensate for lower Isp. The high propellant density results in a volume requirement similar to the best hydrazine systems. The Mars landing mission requires only one cold start on the catalyst, which simplifies thruster development.

Launch safety hazards are benign, given low prelaunch pressure and much higher TLV's (threshold limit values) for human exposure to the vapors. Autodecomposition slowly raises the tank pressure from atmospheric (prelaunch) to system start pressure (50-500 psi range) during interplanetary cruise. The interplanetary cruise propulsion could provide settling burns (midcourse corrections?) to vent excess oxygen, which could even be stored in another tank to supply RCS jets. With some modifications, this system could also provide all the cruise propulsion.

Material compatibility with $\mathrm{H} 2 \mathrm{O} 2$ eliminates titanium and favors polyethylene highly, without especially favoring aluminum or stainless steel. Stainless steel is easier to weld.

Polyethylene results in an autodecomposition rate 50 times lower than stainless steel or aluminum. The 17 liter sphere has a radius of $16 \mathrm{~cm}$ and a volume/surface ratio of $5.3 \mathrm{~cm}$, close to that of a standard $\mathrm{H} 2 \mathrm{O} 2$ material compatibility test (Rocketdyne, 1967). The 2-liter ullage would hold 140 grams of oxygen at 50 atmospheres ( $725 \mathrm{psi})$. The $20 \mathrm{~kg}$ propellant load contains $9.4 \mathrm{~kg}$ of active oxygen, so a $1.5 \%$ active oxygen loss (AOL) could be tolerated at .03\% AOL per week over the 1-year interplanetary cruise. Stainless steel results in a decomposition rate several times higher than this, but polyethylene AOL is as low as $.005 \% \mathrm{AOL} /$ week at room temperature. It would therefore be acceptable for the tank's internal polyethylene coating to be missing over a small area (e.g. near welds), but it would need good adhesion.

Alternatives include low-cost homemade tanks without welds (thin-walled tubing with plastic end plugs). Advanced packaging schemes include building the repressurization system (pump, gas gen, etc.) into the tank. Generally, aggressive hardware can be developed in an environment where occasional explosions are tolerable. With toxic propellants, not even leaks are tolerable. 


\section{High pressure pump-fed nontoxic monopropellant hydrogen peroxide}

This is a nontoxic version of ASTRID with lower Isp. The hardware is entirely different due to propellant-material compatibility, oxidizing warm gas, and different catalyst. The tank can theoretically be made of thin polyethylene only, but it is probably a coating inside very thin stainless steel.

\begin{tabular}{lcccc} 
& manufacturer & part $\mathrm{nr}$ & quantity $\mathrm{x}$ mass & total mass, $\mathrm{kg}$ \\
\hline 17l tank & custom & $1 \times 0.5 \mathrm{~kg}$ & 0.5 \\
high pressure thrusters & custom & $4 \times 0.3$ & 1.2 \\
high performance piston pumps & & $1 \times 0.5$ & 0.5 \\
gas generator & estimate & & $1 \times 0.4$ & 0.4 \\
plumbing, iso valves, fill valves & misc. &. & 1.0
\end{tabular}

Total mass of key components: $\quad 3.6$

Issues: $\quad$ 1. no hardware exists

2. slow decomp. in low pressure tank probably requires cruise venting

3 . is an unpressurized tank of $90 \% \mathrm{H} 2 \mathrm{O} 2$ a range safety difficulty?

\section{3. warm gas pressurized nontoxic bipropellant system using new components}

The high ox/fuel ratio and the need for catalytic thrusters makes this system look like option 11 with a small kerosene tank added on. The fuel tank needs a diaphragm since it is pressurized by warm oxygen. This propellant combination is not hypergolic when cold (a safety advantage), but decomposed $90 \% \mathrm{H} 2 \mathrm{O} 2$ is hot enough to ignite the fuel. The thrusters need fuel injectors and must be designed for much higher temperatures than the monoprop version.

component

$81 \mathrm{H} 2 \mathrm{O} 2$ tank

21 kerosene tank

$350 \mathrm{~N}$ high pressure thruster pump gas generator plumbing, iso valves, fill valves manufacturer

custom

custom

custom

estimate

estimate

Total mass of key components:

$\begin{array}{ccl}\text { part } \mathrm{nr} & \text { quantity } \times \text { mass } & \text { total mass, } \mathrm{kg} \\ & 1 \times 1.1 \mathrm{~kg} & 1.1 \\ \text { estimate } & 1 \times 0.3 \mathrm{~kg} & 0.3 \\ & 3 \times 0.4 & 1.2 \\ & 1 \times 0.1 & 0.1 \\ \text { misc. } & 1 \times 0.1 & 0.1 \\ \text { mat } & & 1.2\end{array}$

Issues: $\quad$ 1. see option 11 issues

2. no flight record for small thrusters using these propellants

This system is one of the lightest. It is the easiest biprop system to do development work on, since the propellants are benign and there are no high performance pumps. On this small scale, a real (rapid cycle run-break-fix) development operation should be possible. 


\section{4. high pressure pump-fed nontoxic bipropellant system using new components}

This system is a combination of options 12 and 13 , since it seems to make sense to pressurize the small fuel tank instead of developing separate, smaller fuel pumps.

\begin{tabular}{llccl} 
component & manufacturer & part $\mathrm{nr}$ & quantity $\times$ mass & total mass, $\mathrm{kg}$ \\
\hline 8 I H2O2 tank, low press & custom & $1 \times 1.1 \mathrm{~kg}$ & 0.3 \\
2 I kerosene tank, high press & custom & $1 \times 0.3 \mathrm{~kg}$ & 0.3 \\
high pressure thrusters & custom & & $1 \times 0.3$ & 1.2 \\
high perf $\mathrm{H} 2 \mathrm{O} 2$ pump & custom & & $1 \times 0.3$ & 0.3 \\
gas generator & estimate & & $1 \times 0.3$ & 0.3 \\
plumbing, iso valves, fill valves & misc. & & 1.2
\end{tabular}

Total mass of key components: $\quad 3.6$

Issues: $\quad$ 1. see previous 3 systems for issues relating to hydrogen peroxide and this propellant combination

This is the highest performance nontoxic storable bipropellant system.

\section{Pulse-capable solid rocket motor (recent missile defense technology)}

This design analysis for a pulsed solid is based on demonstrated hardware, the Thiokol LEAP miniature hover vehicles. In two different hover tests (1993 and 1994), the $1.6 \mathrm{~kg}$ solid LEAP propellant grain burned for 17 seconds, with a total thrust of $200 \mathrm{~N}(45 \mathrm{lb})$ at a sea level Isp of $215 \mathrm{sec}$. The total thrust was continuous, with $133 \mathrm{~N}$ (30 lb) vertical, $44 \mathrm{~N}$ $(10 \mathrm{lb})$ horizontal, and $22 \mathrm{~N}(5 \mathrm{lb})$ for RCS, The vacuum version of the solid LEAP propulsion system has thrust levels and Isp about 1.2 times higher than the sea level numbers. The hover-proven Thiokol solid LEAP propulsion system included $2 \mathrm{~kg}$ of inert hardware, or a propellant fraction of 1.6/3.6=0.44. Data on the LEAP hardware were obtained from Dave McGrath and Tom Kirschner (1995).

It is interesting to note that the hover time was the same for two different payload masses, which illustrates that pulsed solids do not deliver the full $\Delta \mathrm{v}$ which can be calculated from mass ratio and Isp, Instead, they deliver a maximum thrust capability for a fixed period of time until the grain is spent. The total initial hover vehicle masses of $7.7 \mathrm{~kg}$ and $9 \mathrm{~kg}$ indicate vertical thrust/mass ratios of $1.8 \mathrm{~g}$ and $1.5 \mathrm{~g}$, respectively. Thus, to hover at $1 \mathrm{~g}$, the vertical thrust duty cycle was $2 / 3$ at most.

If a pulsed solid motor could use propellant as efficiently as a liquid rocket, $13 \mathrm{~kg}$ of propellant would be needed for the $100 \mathrm{~kg}$ Mars lander to achieve $350 \mathrm{~m} / \mathrm{s} \Delta \mathrm{v}$. A more accurate calculation is independent of delivered $\Delta v$, for a solid grain having continuous combustion. In order to support a burn time of $40 \mathrm{sec}$ (after Viking), at a maximum thrust of $1000 \mathrm{~N}$ at Isp $=253 \mathrm{sec}$, the required propellant mass would be $16 \mathrm{~kg}$.

This total propellant quantity would be met if 10 units of the proven hover design are used. If the burn rate of the grain is slowed to obtain 20 seconds of combustion, operating them in 2 sets of 5 units would deliver thrust for $40 \mathrm{sec}$. Vacuum performance at the slower 
burn rate would result in $1000 \mathrm{~N}$ of thrust from 5 units, precisely the requirement. However, the horizontal divert thrusters would have to be redirected. The system masses are:

component

propellant grain, $40 \mathrm{sec}$ burn time, $1000 \mathrm{~N}$ max thrust, Isp=253 $\mathrm{s}$

solid propulsion system hardware (case, valves, igniters, etc)

Total propulsion mass including propellant (10 solid mini hover units): 36

This total mass is greater than that of any of the liquid system options plotted in Figures 5 and 6. The solid is not shown on the charts because a direct comparison at the level of design detail considered may not be entirely fair.

Issues: $\quad$ 1. Required propellant can be reduced by careful design (see below)

2. Hardware mass can be reduced by eliminating multiple thrust axes

3. Cruise spacecraft power system may be less massive since solid propellant need not be kept warm

To some extent, the extra $3 \mathrm{~kg}$ of propellant and the "wasted" $\Delta v$ could be reduced if the descent trajectory and the propellant grain(s) are both designed with careful consideration of the characteristics of pulsed solids. Primarily, the total burn time must be minimized, which might not ordinarily be done if the trajectory is designed with liquid propulsion in mind. Also, if the maximum $1000 \mathrm{~N}$ thrust is only need initially and can later be reduced closer to the Mars weight of the vehicle $(-400 \mathrm{~N})$, a dual grain approach would work. The second slower burning grain would reduce the total amount of propellant required. Unfortunately, such a detailed trajectory analysis is beyond the scope of this propulsion study.

A pulsed solid design proposal (Tom Kirschner, Thiokol) optimized for Mars landing has thrust in the vertical axis only (plus roll control), and is $65 \%$ propellant by mass. Assuming this can be achieved at the required size and thrust level, mars landing propulsion for a $100 \mathrm{~kg}$ vehicle would consist of $16 \mathrm{~kg}$ propellant, and $9 \mathrm{~kg}$ of inert hardware. The $25 \mathrm{~kg}$ total is close to the mass of the scaled Viking system. It would be lighter than some of the liquid systems, but heavier than the best. However, it must be cautioned once again that while the level of design detail considered in this study permits fair comparisons of one liquid system with another, the vast differences between liquid and solid propulsion result in a less accurate comparison. For example, the mass of other spacecraft systems can be reduced as a secondary effect of using solid propellant, because it packs densely and needs no heaters. It is recommended that solid propulsion be kept under consideration for future Mars missions. 


\section{Propulsion options for a $10 \mathrm{~kg}$ Mars lander}

The scaling limitations of flight-proven components relative to the needs of microspacecraft propulsion systems are strikingly illuminated when the smallest Mars landers are considered. Terminal propulsion options for $10 \mathrm{~kg}$ landers are presented below, and compared graphically in Figure 7. The assumptions are:

Thrust range for $10-15 \mathrm{~m} / \mathrm{sec}^{2}$ deceleration: Landing mass ( $w /$ propellant after 'chute jettison): Propellant mass for $\Delta \mathrm{v}=350 \mathrm{~m} / \mathrm{s}$ : monopropellant hydrazine (Isp $=230 \mathrm{~s}$ ) standard bipropellants (Isp $=310 \mathrm{~s}$ )

hydrazine fuel biprops (Isp $=310 \mathrm{~s}$ ) nontoxic monopropellant (Isp $=160 \mathrm{~s}$ ) nontoxic bipropellants (Isp $=280 \mathrm{~s}$ ) Total RCS impulse:

$100-150 \mathrm{~N}(23-34 \mathrm{lb})$ $10 \mathrm{~kg}$ $1.5 \mathrm{~kg}$ (1.5 liters)

$1.1 \mathrm{~kg}(.7 \mathrm{~kg} \mathrm{~N} 2 \mathrm{O} 4+.4 \mathrm{~kg} \mathrm{MMH})$ (0.47 liters each)

$1.1 \mathrm{~kg}(.6 \mathrm{~kg} \mathrm{~N} 2 \mathrm{O} 4+.5 \mathrm{~kg} \mathrm{~N} 2 \mathrm{H} 4)$

$2.0 \mathrm{~kg}$ of $90 \% \mathrm{H} 2 \mathrm{O} 2$ (1.5 liters)

$1.2 \mathrm{~kg}(1.06 \mathrm{H} 2 \mathrm{O} 2+.14 \mathrm{HC})$ pulse-capable solid propellant (Isp $=253 \mathrm{~s}$ )

The $1 \%$ RCS requirement may be optimistic for cases which have only one central maneuvering engine, because all 3 axes must have RCS. Essentially, this would require that RCS moment arms be several hundred times the misalignment between the maneuvering thrust vector and the vehicle center of gravity.

System options considered and described below

1. Viking terminal descent propulsion masses scaled down by factor of 56

2. conventional blowdown hydrazine with flight-proven spacecraft components

3. conventional regulated hydrazine with flight-proven spacecraft components

4. high pressure blowdown hydrazine using ullage nitrogen for RCS

5. warm gas pressurized hydrazine at moderate to high pressure, warm gas RCS

6. conventional spacecraft biprop technology with flight proven components

7. missile defense biprop technology based on Army-Hughes-Kaiser-Marquardt LEAP

8. warm gas pressurized monoprop hydrogen peroxide

9. warm gas pressurized nontoxic bipropellants

10. pump-fed hydrogen peroxide with warm gas pressurized kerosene

11. pulse-capable solid derived from miniature missile defense propulsion

General comments on $10 \mathrm{~kg}$ landers and Figure 7

For the micrometeorology mission proposed by NASA Ames, landing legs are not even needed if the communication antenna is omnidirectional. The tiny lander would impact on the thruster(s) with the few $\mathrm{m} / \mathrm{sec}$ of impact velocity. If directionality is not important for the spacecraft, it would be ok for it to tip over after landing.

The systems in Figure 7 have greater mass variations than in Figures 5 and 6, because existing components used on conventional spacecraft are relatively much heavier on this tiny scale. It is clear that liquid RCS thrusters are too heavy, and gas RCS jets are shown on all but one option. The lightest system doesn't exist, but nontoxic propellants should reduce development cost and difficulty. It is significant that standard components \& systems are so heavy that implementing innovative system concepts with custom hardware would result in an improvement even with low-Isp nontoxic monopropellant. 
1. Viking terminal descent propulsion masses scaled down by factor of 56

Viking's $84 \mathrm{~kg}$ of hydrazine is scaled to the $1.5 \mathrm{~kg}$ required for a $10 \mathrm{~kg}$ lander.

\begin{tabular}{lllcl} 
& & & & $\bullet$ \\
component & manufacturer & part nr & quantity $\times$ mass & $\begin{array}{l}\text { scaled } \\
\text { total mass, } \mathrm{kg}\end{array}$ \\
\hline 2 spherical tanks & PSI & & $2 \times \sim 10 \mathrm{~kg}$ & .36 \\
$600 \mathrm{lb}$ main thruster & Olin & & $3 \times 7.7$ & .41 \\
5 lb roll thruster & Olin & MR-50 & $4 \times 0.8$ & .06 \\
plumbing, iso valves, fill valves & misc. & (estimate) & .10 \\
& & &. & .93 \\
Total mass of key components: & & &
\end{tabular}

This scaling is theoretical only, as smaller conventional components tend to have greater mass than would be expected from linear scaling.

\section{2. conventional blowdown hydrazine with flight-proven spacecraft components}

This system is identical in concept to Viking. Three main thrusters enable pitch/yaw control. Sufficiently large available thrusters would provide adequate thrust over a blowdown pressure range of 200-100 psi.

\begin{tabular}{lllcl} 
component & manufacturer & part nr & quantity $\times$ mass & total mass, $\mathrm{kg}$ \\
\hline 3 liter spherical tank & custom & & $1 \times .3 \mathrm{~kg}$ & 0.30 \\
80-40 N thrusters & Olin & MR-120 & $3 \times .41$ & 1.22 \\
5-.25 N roll thruster & Olin & MR-103C & $4 \times 0.33$ & 1.33 \\
plumbing, iso valves, fill valves & misc. & & 0.30
\end{tabular}

Total mass of key components:

Given limited component selection, the alternative of smaller thrusters operating at their maximum capability would result in six MR-106C units totalling $2.3 \mathrm{~kg}$. If the six are angled to obtain roll torques as well a pitch \& yaw, a net thruster mass saving of $.25 \mathrm{~kg}$ would be realized.

\section{3. conventional regulated hydrazine with flight-proven spacecraft components, N2 RCS}

A single existing thruster is adequate if operated at its highest feed pressure, $355 \mathrm{psi}$. The $1 \%$ RCS requirement results in a nitrogen mass of $.06 \mathrm{~kg}$ ( $4 \%$ of $\mathrm{N} 2 \mathrm{H} 4$ mass), given the factor of 4 less Isp. Additionally, $.04 \mathrm{~kg}$ of nitrogen is required for propellant tank pressurization.

component manufacturer part $\mathrm{nr}$ quantity $\mathrm{x}$ mass total mass, $\mathrm{kg}$ 1.5 liter spherical tank custom $110 \mathrm{~N}$ thruster Olin MR-120 $1 \times .25 \mathrm{~kg}$ 0.25 nitrogen nitrogen tank custom $.5 \mathrm{~N} \mathrm{N2}$ RCS jets Moog regulator, plumbing, iso valves, fill valves misc. $1 \times .41$

0.41

0.10

Total mass of key components: 1.5 


\section{4. high pressure blowdown hydrazine using ullage nitrogen for RCS}

A single advanced thruster developed for missile defense provides adequate thrust at the low end of a 1200-500 psi blowdown range. Using tank ullage gas for attitude control results in a single relatively large tank, eliminating nitrogen tank development. N2 density at $1200 \mathrm{psi}$ is $93 \mathrm{~g} / \mathrm{l}$, so an extra liter or so is needed for 60 grams of RCS gas. A 3.7 liter tank begins with 2.2 liters of $\mathrm{N} 2$ at $1200 \mathrm{psi}$ (205 grams) and ends with 3.7 liters at 500 psi (143 g).

\begin{tabular}{lllcl} 
& manufacturer & part nr & quantity X mass & total mass, $\mathrm{kg}$ \\
\hline component & custom & $1 \times 0.9 \mathrm{~kg}$ & 1.0 \\
advanced thruster & Olin & MR-125 & $1 \times .2$ & 0.2 \\
nitrogen & & & & 0.2 \\
.5 N N2 RCS jets & Moog & & $6 \times .03$ & 0.18 \\
plumbing, iso valves, fill valves & misc. & & 0.24
\end{tabular}

Total mass of key components:

drawback is large volume requirement, \& heavy tank. main advantage is simplicity, small number of components

5. warm gas pressurized hydrazine at moderate to high pressure, warm gas RCS While gas jet RCS can decrease thruster mass greatly, nitrogen storage is heavy as previous examples illustrate. Also the fixed nitrogen supply is obviously risky, and requires margin. An alternative design using the advanced thruster but a small lightweight tank would be a warm gas pressurized system. Decomposed hydrazine would maintain ullage pressure and be used for attitude control.Warm gas attitude control jets would need to be developed, and there may be thermal issues in tank design for this short mission.

\begin{tabular}{lllll} 
component & manufacturer & part $\mathrm{nr}$ & quantity $\times$ mass & total mass, $\mathrm{kg}$ \\
\hline 1.5 liter spherical tank, 500 psi op & custom & $1 \times .4 \mathrm{~kg}$ & 0.4 \\
advanced thruster & Olin & MR-125 & $1 \times .2$ & 0.2 \\
.5 N warm gas RCS jets & custom & $6 \times .04$ & 0.2 \\
pump, g.g., plumbing, iso valves, fill valves & misc. & & 0.4
\end{tabular}

Total mass of key components:

6. conventional spacecraft biprop technology with flight proven components

This option is expected to be dominated by thruster mass, as are the other Mars landing systems based on conventional spacecraft components. The thruster listed below is used for the Space Shuttle RCS vernier.

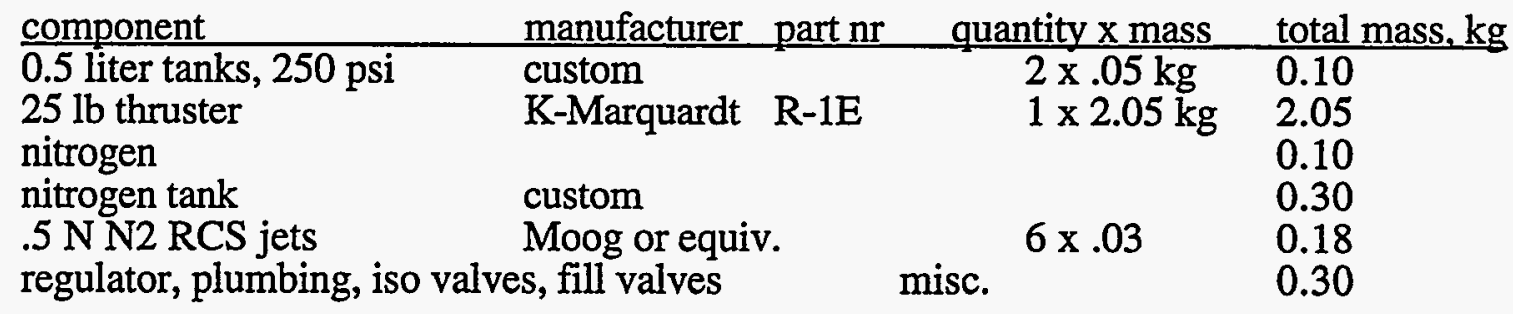

Total mass of key components: 
7. missile defense biprop technology based on Army-Hughes-Kaiser-Marquardt LEAP The $6 \mathrm{~kg}$ Army-Hughes LEAP (Lightweight ExoAtmospheric Projectile) defense vehicle has a divert system which is considered to be the smallest liquid rocket propulsion ever flown. Its $\Delta v$ capability is $380 \mathrm{~m} / \mathrm{s}$ as reported by Bryant (1984). As built by KaiserMarquardt, the propulsion system dry mass is $2.13 \mathrm{~kg}$, and $0.83 \mathrm{~kg}$ propellant can be carried in piston tanks. The R-46 thruster delivers $34 \mathrm{lb}$ at 1400 psia feed pressure, with N204/N2H4 in a 1.1 mixture ratio. The K-Marquardt LEAP propulsion system also used miniature 1-lb warm gas attitude control jets fed by a monopropellant hydrazine gas generator.

The tiniest known diaphragm tank is Arde part number C4369, made for missile defense liquid propulsion. Its size data are 3.4 inches o.d., 77 grams mass, 0.31 liters fill, 0.29 expel, and $880 \mathrm{psi}$ operating pressure at a 1.5 safety factor. The table below assumes the tank mass is increased to 120 grams for operation at the $R-46$ feed pressure.

\begin{tabular}{|c|c|c|c|c|}
\hline component & manufacturer & part nr & quantity $x$ mass & total mass, $\mathrm{kg}$ \\
\hline $0.31, \emptyset 3.4$ in diaphragm tank & Arde & C4369 & $4 \times 0.12 \mathrm{~kg}$ & 0.48 \\
\hline $4 \mathrm{lb}$ lightweight thruster & K-Marquardt & $\mathrm{R}-46$ & $3 \times 0.1 \mathrm{~kg}$ & 0.3 \\
\hline LEAP helium tanks \& reg. & K-Marquardt & & & 0.3 \\
\hline EAP gas gen \& RCS jets & K-Marquardt & & & 0.2 \\
\hline gulator, plumbin & f:11 -1 & & isc. & 0.2 \\
\hline
\end{tabular}

Total mass of key components:

LEAP has no carbon in the exhaust, which may be desired for Mars landing.

An alternative to pitch/yaw RCS is gimballing the single thruster. On this tiny scale, it seems likely that structure, bearings, motors and power electronics would be heavier than RCS jets, but a complete comparison would need to include the RCS propellant mass in each case.

8. warm gas pressurized monoprop hydrogen peroxide

This would be the easiest unconventional option to implement due to the single nontoxic propellant: It is similar to the warm gas pressurized hydrazine system, except that the hardware design is more aggressive because greater risk is acceptable in development testing, especially on this tiny scale.

\begin{tabular}{lccl} 
component & manufacturer part $\mathrm{nr}$ & quantity $\times$ mass & total mass, $\mathrm{kg}$ \\
\hline 1.5 liter tank, $400 \mathrm{psi}$ op & custom & $1 \times .4 \mathrm{~kg}$ & 0.3 \\
short-life thruster & custom & $1 \times .3$ & 0.3 \\
$.5 \mathrm{~N}$ RCS jets & custom & $6 \times .03$ & 0.2 \\
pump, g.g., plumbing, iso valves, fill valves & misc. & & 0.2
\end{tabular}

Total mass of key components: 


\section{Propulsion options for a $100 \mathrm{~kg}$ Mars hopper}

Short hops for rotations or translations up to several meters are entirely feasible with residual landing propellant at $<10 \mathrm{~m} / \mathrm{s}$ per hop. This type of maneuver would be ideal for reorienting fixed-mount cameras on tiny landers, including obtaining stereo image pairs. The propulsion design issue is not increased $\Delta v$, but survivability which includes avoidance of propellant freezing, fluid leakage, and catalyst degradation.

For longer hops, longevity issues must be addressed, but achieving significantly greater $\Delta \mathrm{v}$ is the major challenge. For example, the terminal landing propulsion system could be designed for a total $\Delta \mathrm{v}$ of $1000 \mathrm{~m} / \mathrm{s}$. After landing, several surface-mobility hops could be performed on a $\sim 1 \mathrm{~km}$ scale.

Thrust range for $10-15 \mathrm{~m} / \mathrm{sec}^{2}$ deceleration: Landing mass ( $w /$ propellant after 'chute jettison): Propellant mass for $\Delta \mathrm{v}=1000 \mathrm{~m} / \mathrm{s}$ :

monopropellant hydrazine (Isp $=230 \mathrm{~s}) \quad 36 \mathrm{~kg}$ standard bipropellants (Isp $=310 \mathrm{~s}$ ) nontoxic bipropellants (Isp $=260 \mathrm{~s}$ ) Total RCS impulse:

$1000-1500 \mathrm{~N}(225-337 \mathrm{lb})$ $100 \mathrm{~kg}$ $28 \mathrm{~kg}(17.4 \mathrm{~N} 2 \mathrm{O} 4+10.6 \mathrm{MMH})$ (12 liters each) $33 \mathrm{~kg}(-29 \mathrm{~kg} \mathrm{H} 2 \mathrm{O} 2+4 \mathrm{~kg} \mathrm{HC})$ $1 \%$ of maneuvering impulse

The increased propellant quantities place a greater emphasis on minimizing propulsion hardware mass than for landing alone. Options based on conventional spacecraft hardware are heavy. Options which should be considered further include:

1. Pressure regulated advanced hydrazine at optimized pressure

2. Pump fed hydrazine at high pressure

3. Pressure regulated advanced bipropellants

4. Pump fed nontoxic bipropellants

Rocket-propulsive hopping over significant distances requires a lot of propellant, the mass of which would have to be traded against the mass of a rover. Hopping is perceived to be very risky, due to the potential for crashing. Limitations relative to the surface mobility requirements of the science community must be carefully weighed. Hopping makes most sense for a tiny lander that is 1) not a highly valued asset, 2) too small to carry a separate rover, and 3) has outlived its usefulness at its original landing site. 


\section{Propulsion for Mars sample return}

As noted earlier, Mars sample return has been studied extensively, and excellent work has been done towards technology to produce propellants on Mars. Whatever the propellant source, the return-to-earth vehicle must have a very high propellant fraction. Therefore, this report emphasizes the design of Mars launcher hardware. Non-cryogenic propellants receive highest priority for storability reasons, and nontoxic propellants are of interest to reduce the development and testing costs of the necessarily unique hardware. Although propellant combinations considered below appear to exclude candidate in-situ produced propellants, the concepts for pump-fed Mars launcher hardware on a small scale could be adapted to in-situ propellants.

One interesting and important question is, "What is the smallest scale on which Mars sample return can be accomplished, and what are the limiting factors?" Minimum size is limited for several reasons, including desired sample size, scaleability of cruise spacecraft functions for return to earth, and recovery of tiny entry vehicles in earth's atmosphere. It is speculated that a return vehicle having significantly less than a $100 \mathrm{~kg}$ Mars launch mass would violate one of these three conditions, so this "limiting mass" is chosen here to set a propulsion design goal. It is notable that a $100 \mathrm{~kg}$ return vehicle could be carried on a Viking-scale lander sent to Mars (without an orbiter) by a Delta 7925 launch vehicle. Essentially, this option would be in the same mission class as the proposed JSC-Martin sample return, but with a smaller return vehicle which needs no in-situ propellant production.

The highest performance (high $\Delta v$, high thrust/weight) rocket stages ever built are earth launcher stages which use pump-fed liquid propulsion. LLNL's ASTRID flight experiment demonstrated that pump-fed propulsion can be implemented on a tiny scale. Therefore, scaling high performance propulsion down for the Mars launcher is credible, and is not expected to set a lower limit on the size of a sample return vehicle.

Propulsion options for a two-stage sample return vehicle having a $100 \mathrm{~kg}$ launch mass are considered below. On this small scale, the number of subsystems must be absolutely minimized. Therefore, it is desirable for the second stage $\Delta \mathrm{v}$ system to also provide the trans-earth cruise functions, including course corrections. Given this longevity requirement for the upper stage, it is logical for the lower stage to provide significantly more than half of the $\Delta \mathrm{v}$ required. This is consistent with designing the first stage to carry the vehicle at least to a low Mars orbit, and perhaps to a higher orbit. Note that higher orbits having longer periods can greatly reduce the thrust/weight requirements for exiting Mars orbit onto a trans-earth trajectory.

If an upper stage sample return spacecraft cannot be built small enough, this "Mars SSTO" first stage would be applicable to Mars orbit rendezvous sample return scenarios, or it could be scaled up.

Requirements and propellants considered for sample return first stage, "Mars SSTO"

Launch mass:

$100 \mathrm{~kg}$

Thrust required for initial thrust/mass ratio of $6 \mathrm{~m} / \mathrm{s}^{2}$ : $600 \mathrm{~N}(135 \mathrm{lb})$

Propellant mass required for $\Delta v=4000 \mathrm{~m} / \mathrm{s}$ : monopropellant hydrazine $(\mathrm{Isp}=230 \mathrm{~s})$ standard bipropellants (Isp $=310 \mathrm{~s}$ )

$83 \mathrm{~kg}$ ( 83 liters)

$73 \mathrm{~kg}(45.5 \mathrm{~N} 2 \mathrm{O} 4+27.5 \mathrm{MMH})$

(31.4 liters each) 


nontoxic monopropellant $(I s p=160 \mathrm{~s})$
nontoxic bipropellants $(\mathrm{Isp}=280 \mathrm{~s})$
in-situ bipropellants $\quad(\mathrm{Isp}=300 \mathrm{~s})$
conventional solids $\quad(\mathrm{Isp}=287 \mathrm{~s})$

nontoxic monopropellant (Isp $=160 \mathrm{~s}$ )

in-situ bipropellants (Isp $=300 \mathrm{~s}$ )

conventional solids $\quad($ Isp $=287 \mathrm{~s})$
$92 \mathrm{~kg}$ of $90 \% \mathrm{H} 2 \mathrm{O} 2$ (67 liters)

$77 \mathrm{~kg}(68 \mathrm{~kg} \mathrm{H} 2 \mathrm{O} 2+9 \mathrm{~kg} \mathrm{HC})$

$74 \mathrm{~kg}(49 \mathrm{~kg} \mathrm{O} 2+25 \mathrm{~kg} \mathrm{CH} 4)$

$76 \mathrm{~kg}$ (53 AP, $12 \mathrm{Al}, 11 \mathrm{CTPB})$

Figure 8 displays the vehicle mass breakdowns graphically, for the options considered below. The graph makes it clear that the total mass of the upper stage, with its Mars sample, would be limited to roughly $15 \mathrm{~kg}$. A second key point is that the mass of first stage hardware in addition to tanks and engines is critical. Lightweight propulsion components are only half of the solution to this problem. Since it is truly a miniature launcher stage, a fully integrated approach to stage design and testing is required. The standard approach used for spacecraft propulsion, namely component selection followed by the design of pluming and structure, is insufficient.

The lightest first stage for a Mars sample return vehicle is not necessarily the one with the least propellant mass, or the one having the lightest propulsion components. The author's favorite propellants for developing a vehicle with these advanced features are the nontoxic biprops. This choice is based on experience at testing advanced miniature rocket hardware. Rocket company and test facility personnel are extremely averse to testing advanced lightweight hardware with toxic propellants (even on a tiny scale!), especially when propellant tanks and heat sources are in close proximity to one another.

Pump fed monopropellant hydrazine

This monopropellant option is directly derived from the flight-demonstrated ASTRID technology. The advantage of this option is that sufficiently lightweight and life-capable thrust chambers and pumps have already been demonstrated.

\section{Conventional spacecraft bipropellants}

Scaling the Marquardt R-4D (3.75 kg) up to meet the thrust level theoretically yields a $5 \mathrm{~kg}$ thruster. Compatible standard tanks on the appropriate scale (e.g. 32 liters) aren't normally qualified for biprops, but would mass roughly $10 \mathrm{~kg}$. This number includes structure needed to accommodate standard spherical tanks, or alternatively it applies to custom cylindrical tanks, considering their lower structural efficiency than spheres. As the graph shows, using proven hardware would eliminate the advantage of bipropellant when compared to pump fed hydrazine.

\section{High pressure regulated biprop}

The viability of this option hinges on tank technology (which is slowly advancing) and low safety factors. The tank capability assumed here is superior to that which has been successfully implemented on miniature missile-defense vehicles of the past decade. For the liquid tanks, operating PV/W was assumed to be $250 \mathrm{k}$ inches, which is close to that of an advanced composite 96-liter hydrazine tank made for TRW (SCI part nr 5221). For perspective, other pioneering composite hydrazine tanks used on Pegasus and the Lockheed Launch Vehicle have PV/W values of $\sim 90 \mathrm{k}$ inch. Taking the higher number results in a pair of $3.5 \mathrm{~kg}$ tanks for operation at 1000 psi. The PV/W of the helium tank is assumed to be $650 \mathrm{k}$ inches, after the Hughes HS-601 helium tank (SCI 464C). The thruster mass is inconsequential, if missile defense components are considered. However, existing miniature thrusters in this class are limited in lifetime so this limitation would need to be addressed with some mass increase.

\section{High pressure pump-fed biprop}

Small pump-fed engines (pumps, gas generators, thrust chambers) having launcher-class thrust/weight (on earth) ratios $\geq 50$ would mass $\leq 1.2 \mathrm{~kg}$ for $600 \mathrm{~N}$ thrust. Low pressure tanks having tens of liters of volume would be affected less by minimum wall thickness 
limitations than the 15-liter ASTRID tank; which could contain 21 times its own mass in hydrazine. Therefore, tankage mass for the Mars launcher could be as low as $2.5 \mathrm{~kg}$. Thruster lifetime would have to be addressed, as explained above.

Pump-fed nontoxic bipropellants

Tank and engine masses are similar to those for the pump fed toxic biprops, except that thruster mass was increased in Figure 8 to allow for catalyst and longer life hardware. Thin tank walls, common bulkheads between fuel \& oxidizer, pumps inside tanks, and possibly recessing thrust chambers into the lower tank, are attractive concepts for producing the lightest weight integrated liquid stage. The necessity of fully integrated testing in flight configuration, along with the likelihood of rupture and spillage during development, is expected to result in an uphill struggle against established safety standards if toxic propellants are used. For example, when LLNL bipropellant pumps were tested with just a few kg of propellants at Kaiser-Marquardt, the heavyweight source tanks and feedlines, both running at low pressure, had to be separated with fuel components on one side of a heavy steel plate and oxidizer on the other side.

Figure 9 illustrates a $100 \mathrm{~kg}$ Mars launcher concept based on pump-fed nontoxic bipropellants. The fuel is pressure-fed from the tank, because it is only a small fraction of the total propellant. Essentially all components are located inside the low pressure hydrogen peroxide tank, so that structure is minimized, packaging is simple, hot parts are liquid cooled, and there are no externally exposed thin liquid lines requiring insulation to avoid freezing.

Pump-fed in-situ propellants

The required propellant quantity is shown in Figure 8, along with a notional tank mass, i.e. the sensitivity of the vehicle design to dewar tank mass is apparent. One interesting capability of cryogenic in-situ propellants (O2 and $\mathrm{CH} 4)$ is that the residual tank ullage gases can be used in gas-fed biprop thrusters for maneuvering in Mars orbit, including possible spin-up for stabilizing the earth return spacecraft.

Solid motor options

An alternative that cannot be overlooked is a small solid motor, scaled slightly from Thiokol's STAR 17 (70 kg propellant, $9.5 \mathrm{~kg}$ inert, Isp=287 s). The standard Orbus family (United Technologies Chemical Systems Division) has similar performance ratios near the size of interest. These motors are spherical, so extra custom structure on the motor case is required to join the upper stage. An advanced technology solid, ASAS (Advanced Solid Axial Stage), has a $93 \%$ motor mass fraction on a smaller scale than required (44 kg propellant), and a classified Isp.

Unfortunately, reaction control propulsion adds significant mass to small solid motors, as the RCS requirement is driven by a solid motor's potentially high thrust vector alignment uncertainty. Solid motors are typically used while spinning, to obviate the RCS requirement. The few nonspinning spacecraft pushed by solid motors include Voyager (out of LEO) and Magellan (Venus orbit insertion). Both included hydrazine RCS on the spacecraft itself, with significant moment arms to minimize the required impulse. An additional drawback of solid motors is a thrust level which is 20 times the Mars launch requirement. The high thrust of solid motors would result in greater structural mass for both stages, as well as requiring more precise and rapid control to reach the desired orbit.

\section{Hybrid motor options}

For completeness, the resurgence of interest in hybrid motors in the propulsion community (especially at several universities and small companies) should not be ignored here. This would be a bipropellant engine, with oxidizer flowing into and combusting with a solid fuel 
grain (e.g. rubber or polyethylene). If the oxidizer is $\mathrm{H} 2 \mathrm{O} 2$, the pressurized fuel grain case would be relatively small due to the high mixture ratio required with $\mathrm{H} 2 \mathrm{O} 2$. The $\mathrm{H} 2 \mathrm{O} 2$ could be pump-fed at high pressure from a low-pressure tank, just as in a pump-fed monoprop system. The $\mathrm{H} 2 \mathrm{O} 2$ would be used for reaction control. Sellers (1995) presents an excellent case for a future generation of low-cost hybrid space motors. Presently, no such motor is commercially available.

Stage design for low mass of associated hardware is key issue

The key factor in realizing the required performance potential for any of the options presented above is not addressed by propulsion technology alone, at least not by propulsion component technology. The task of designing a lightweight stage which weighs little more than the sum of propulsion components is a major challenge. To date, this challenge has never been faced by a spacecraft. Lessons from the best earth launch vehicles therefore must be included in the design process for Mars sample return. Packaging approaches which reduce extra plumbing and structural mass begin with the use of stacked cylindrical tanks, but include more subtle concepts such as a common bulkhead to separate the fuel \& oxidizer (e.g. Atlas \& Centaur), and carrying components inside the tanks (e.g. Saturn V).

\section{Mars sample return upper stage}

It is assumed here that the $100 \mathrm{~kg}$ Mars launcher would include a $15 \mathrm{~kg}$ upper stage for earth return from a relatively high (but lower than Viking) Mars orbit. The requirements are:

Initial mass:

Thrust required for initial thrust/mass ratio of $2 \mathrm{~m} / \mathrm{s}^{2}$ :

Propellant mass required for $\Delta \mathrm{v}=2000 \mathrm{~m} / \mathrm{s}$ : monopropellant hydrazine (Isp $=230 \mathrm{~s}$ ) standard bipropellants (Isp $=310 \mathrm{~s}$ )

nontoxic monopropellant (Isp $=160 \mathrm{~s}$ ) nontoxic bipropellants (Isp $=280 \mathrm{~s}$ ) in-situ bipropellants (Isp $=300 \mathrm{~s}$ )
$15 \mathrm{~kg}$

$30 \mathrm{~N}(6.7 \mathrm{lb})$
$8.8 \mathrm{~kg}$ (9 liters)

$7.2 \mathrm{~kg}(4.5 \mathrm{~N} 2 \mathrm{O} 4+2.7 \mathrm{MMH})$

(3.1 liters each)

$10.8 \mathrm{~kg}$ of $90 \% \mathrm{H} 2 \mathrm{O} 2$ (7.7 liters)

$7.8 \mathrm{~kg}(6.8 \mathrm{~kg} \mathrm{H} 2 \mathrm{O} 2+0.9 \mathrm{~kg} \mathrm{HC})$

$7.4 \mathrm{~kg}(4.9 \mathrm{~kg} \mathrm{O} 2+2.5 \mathrm{~kg} \mathrm{CH} 4)$

The lower $\Delta v$ requirement for the earth return spacecraft reduces its propellant mass fraction to roughly half, from about three-quarters for the Mars launcher stage. Also the acceleration requirement is greatly reduced. This lower raw performance, along with the $\sim 1$-year operating lifetime for course corrections and earth entry RCS, suggests that a pressure-fed propulsion system is appropriate.

Warm gas pressurized systems are expected to have less hardware mass than if stored inert gas is used.

If cryogenic in-situ derived propellants are used for the Mars return upper stage, storage during the earth return cruise would be a problem to solve.

Proposed test for Mars sample return vehicles

Complete Mars sample return vehicles can be tested starting in earth orbit, or alternatively as the upper two stages of a 3-stage miniature earth launcher. For example, the $100 \mathrm{~kg}$ Mars launcher described here could be put inside a fairing and stacked atop a standard solid motor massing just hundreds of kilograms. The final stage of the vehicle would reach earth orbit, whereupon a life test of its cruise functions would begin. 


\section{General propulsion design issues}

The design of launcher and spacecraft propulsion is highly dependent on maneuvering requirements, but also on absolute size (mass), thrust duty cycles, operation in gravity or microgravity, and on requirements for reliability and lifetime.

The two basic maneuvering performance parameters, the $\Delta v$ and thrust/weight of a vehicle, can be conflicting goals. This is so because the propulsion designer must choose whether to use larger thrusters or to carry more propellant within a given mass budget, if both high thrust/weight and high $\Delta \mathrm{v}$ are required for aggressive maneuvering. This is the case for launches from earth or Mars, and to a lesser extent for planetary orbit insertion maneuvers as well as lunar landing and return. Figures 1 and 2 of this report illustrate the basic performance parameters, for both mission requirements and system capabilities.

The thrust duty cycle is a major consideration, particularly the partitioning of impulse between long maneuvering burns and small thrust pulses for attitude control and stationkeeping. For example, the conventional spacecraft use of spontaneously catalyzed monopropellant, or hypergolic bipropellants, is driven by the relative incompatibility of active ignition with many short thrust pulses.

Other issues, which greatly affect the design of real propulsion systems, include lifetime and reliability. Long life reliable operation is usually achieved through the use of redundant components, along with careful attention to avoiding fluid leakage losses. Note that redundancy of components fundamentally increases the potential for leakage losses. The need for redundancy and low leakage has resulted in the adoption of specialized valves to isolate parts of a system from one another.

Generally, redundancy is more difficult to achieve for major system components than for minor system components. For standard spacecraft which require long life at low thrust, propellant carrying capacity can be thought of as a major system component whereas thrusters are a minor component. Since thrusters are relatively small, it is easier to include redundant thrusters than redundant tanks. Redundancy of thrusters is more difficult to achieve for missions that require high thrust/weight. As examples, the Viking lander, Apollo spacecraft, and earth launch vehicles have almost no redundancy of their main thrusters or engines.

Although the most fundamental aspects of rocketry are independent of scale, many secondary effects and practical limitations result in a great dependence of propulsion design on absolute size.

\section{Typical propulsion requirements}

The capabilities of propulsion technologies which presently exist are highly dependent on the needs of missions which are flown most often. Generally, two extremes of propulsion requirements exist. The first is launcher propulsion, characterized mainly by the maneuvering requirement for high acceleration and $\Delta v$ together, in one continuous burn. Operational lifetimes are just a few minutes, and restartability is not needed. The second extreme is satellite orbit maintenance (attitude control, GEO stationkeeping, and LEO drag makeup), which is characterized by low acceleration and the need for long life operation with many short thrust pulses.

For obvious reasons, launcher propulsion exists mainly on a large size scale, while satellite propulsion technology has been developed on a smaller scale. On a still smaller scale 
( $<100 \mathrm{~kg}$ spacecraft), the availability of propulsion technology is very limited, because of the larger typical size of historically useful payloads.

A number of missions have propulsion requirements between the above two extremes. A common mission is transferring spacecraft from LEO to GEO. This has resulted in upper stages that have less acceleration and $\Delta \mathrm{v}$ than the main stages of launch vehicles, while also being capable of several restarts over operational lifetimes of days. Less common missions which have requirements similar to those of LEO-GEO transfer include transfers to interplanetary trajectories, orbit insertions, and lunar landing and return. 


\section{Review of LLNL pumped propulsion as flown on ASTRID}

Recent work has advanced small rocket propulsion technology in new directions, and has been particularly revolutionary toward higher performance. It must be appreciated that this has been possible in part due to minimal attention to lifetime and reliability standards that spacecraft designers have become accustomed to expecting from conventional mature, evolutionary technology. Therefore, adapting recent advances for use on long-life spacecraft is not a trivial task. The list below addresses these issues for LLNL's high performance pump-fed propulsion (Whitehead, Pittenger, Colella, 1994).

Items required for long life space flight that the ASTRID experiment did not include

1. Attitude control thrusters

Liquid thrusters don't exist for 50 psi tank pressure or 1000 psi pump pressure.

Warm gas jets have been demonstrated but are not readily available.

2. Microgravity tank (none exist which are specifically designed for low pressure \& mass)

3. Pyro valves, all-welded plumbing (normally required by launch range safety people)

4. Wet storage life without leakage either before or during operational period.

5. Laboratory qualification testing of complete propulsion system.

6. Vacuum chamber testing of propulsion system.

7. Design and qual testing for launch vehicle vibration (especially tank).

8. Design and qual testing for space thermal environment.

9. Ensuring compatibility of propulsion with vibration-sensitive instruments (e.g. QRS)

10. Operation without last-minute changes based on real-time thinking in the field.

11. Delivery of a particular precise thrust level set in advance.

\section{Improvements to LLNL pumped propulsion as flown on ASTRID}

Initial ground-breaking demonstrations of revolutionary technology do not automatically lead to mature, off-the-shelf, reliable, frozen designs that are applicable to a wide variety of mission requirements. Instead, much is learned from each new application when technology is rapidly advancing, and lessons learned can greatly improve subsequent implementations. For example, the table below compares two very different configurations for reciprocating pumps, based on ASTRID experience and subsequent thinking about design alternatives.

Independent pump chambers (on ASTRID) positive overlap of delivery strokes requires tank pressure for refill requires exhaust press $\ll$ tank press discharge pressure independent of tank pressure a single pair of chambers can cancel vibration difficult to cycle without liquid independent refill stroke ends with impact can have backup static liquid seals can bootstrap off either pump, starting below valve friction threshold as long as one intake open
Mechanically linked pump chambers mechanism must reverse to continue can draw from unpressurized tank can discharge exhaust at higher press potential for POGO if scaled up a pair of pairs is needed to cancel vib. easily cycled for dry testing piston smoothly reverses direction redundant dynamic seals, frict not crit ready chamber must open intake \& close other's exhaust, friction issue

The relative importance of the various advantages and disadvantages listed above remain unquantified. A test of the mechanically-linked type of pump could provide this significant new knowledge at a modest cost, relative to the cost of implementing this miniature pumpfed technology on a space mission. 


\section{The case for nontoxic or less toxic propellants}

The potential advantages to be gained by using less toxic propellants have been mentioned throughout this report. This section summarizes the arguments.

Conventional spacecraft propulsion technology is mature, highly refined, and advances occur only in small evolutionary steps. All standard liquid propellants are toxic, so testing is dangerous and costly. The number of facilities in the U.S. where such rocket testing is permitted is decreasing. Managers of these test facilities are keenly interested in avoiding any test failures which might restrict future operations by damaging their facility or releasing toxic propellants. The mature state of conventional technology and the sentiments of test facility personnel are well matched. Typically, tests involve hardware that is just slightly improved from an earlier design, and there is a high likelihood of test success. Each test is very carefully planned and conducted, with extensive, highly accurate data collection, which results in a high expense. Essentially, development testing of radically new ideas is outside the realm of what mature rocket companies typically do.

In contrast, cost-effective development of revolutionary technology requires a completely different approach to testing. Frequent, low-cost high-risk tests are required, with significant learning at each step and major design changes from one test to the next. Data collection is inexpensive, because each test need only answer a few simple but critically important questions. The use of nontoxic propellants can enable implementation of this type of testing operation. If the goal is to push hardware to the limit, the limits must be found. Therefore, explosions must be defined as test results, and not carry the stigma of "accident" or "incident". There are many minimally-toxic fuels available, including hydrocarbons and alcohols. The choice of storable liquid oxidizers, however, is very limited (Cort et al 1995). Hydrogen peroxide has received widespread interest. It is notable that explosions release water and oxygen into the environment, a result that is not easily improved upon.

If rocket technology is to advance rapidly or to be revolutionized in the future, some of the brightest young engineers must be attracted to the field each year. The ideal way to do this is by providing interesting, hands-on laboratory experience at universities, just as is currently the case with computer engineering and many other endeavors. Rocket experiments with hydrogen peroxide are now occurring at several universities, including at the University of Surrey, the U.S. Air Force Academy, and Purdue.

Even if rocket technology development with toxic propellants could be made easier and safer, toxicity is a major drawback for field testing or integrated testing of spacecraft. It would be unthinkable to not test a spacecraft computer, power system, communication system, or scientific instrument, because the cost of letting flaws go unnoticed is too high. Yet today's standard for spacecraft propulsion is to design, build, and fly with little or no functional testing at the system level. In an attempt to compensate for the lack of complete system testing, people overemphasize the importance of flight heritage for the individual components. As a result, spacecraft propulsion technology has been advancing only very slowly because there is little room for creativity or revolutionary approaches in system design. Designing a new system is presently a matter of component selection followed by a packaging and plumbing exercise. Supposedly the technology is refined enough and understood well enough that this approach works, but there have been some major disappointments, including Mars Observer and several large communication spacecraft.

It would be unthinkable to send a surface rover vehicle to Mars without extensive terrestrial testing in representative terrain. At the same time, landing on Mars is considered to be the riskiest part of a mission, but terrestrial earth testing of Mars landers on representative 
terrain is rarely discussed. Given today's environmental laws, safety rules, and liability fears, terrestrial flight testing is extremely difficult or impossible (i.e. expensive and timeconsuming) if toxic propellants are involved.

For example, hover tests of miniature missile defense vehicles at Edwards were restricted to a tightly controlled indoor environment even though thousands of acres of desert were readily available. Plans to flight test LLNL's miniature propulsion system at the Nevada Nuclear Test Site (c. 1992) never made it past the hydrazine ES\&H (environment, safety and health) stage. Off-loading toxic propellants from the Space Shuttle RCS and OMS systems is a major issue in "safeing" the vehicle after landing. In contrast, the DC-X uses nontoxic propellants (oxygen and hydrogen), and operations have been demonstrated to be much cheaper. Another example is that the Apollo lunar module pilots trained on a flying vehicle which used nontoxic propellants, also at White Sands. Air-breathing jet engines were used to support most of the weight of the Bell-built vehicle, while hydrogen peroxide thrusters were used by the astronauts to effect control.

A Mars lander designed with nontoxic propellants could readily be hover-tested on earth, and this should be done to help ensure mission success. This is especially so if the Mars lander is designed for autonomous navigation with lateral maneuvering for obstacle avoidance. Any vehicle that is intended to perform repeated propulsive hopping must certainly be tested extensively to assuage fears over the risk of damage upon re-landing.

After technology development and qualification testing comes the mission launch itself. Propellant toxicity concerns at launch ranges have a significant impact on spacecraft propulsion design. The standard of all-welded plumbing joints is driven in part by leakage fears at launch ranges. The all-welded approach is expensive, time consuming, and severely restrictive of design changes. It adds an extra design-change step between disassembleable test hardware and flight hardware. The Russian Soyuz manned reentry capsule uses monopropellant hydrogen peroxide for RCS, and fittings are used on the plumbing instead of welds (Sanders, JSC, private communication, 1995).

Any claim that space propulsion technology is mature and needs no revolutionary advances seems weak, when the content of this report is considered. In particular, creating gas (for pressurant and RCS) from a liquid is an obvious advance that should be implemented on many spacecraft. However, the conventional approach is still to carry stored inert gas in potentially dangerous high pressure tanks, which results in significant extra weight and volume occupied. The use of nontoxic propellants is expected to dramatically reduce the cost and time required to make these revolutionary advances in technology, as well as the cost of flight hardware qualification, and integrated system testing.

Advances in propulsion system design, as opposed to component design, are generally impossible with the conventional approach. For example, there are rocket companies which develop, test, and sell thrust chambers, and they rarely work with flightweight tanks, let alone complete systems. System designers must work with standard components. The list below provides examples of system advances which seem to require a switch to nontoxic propellants.

Advanced ideas which aren't acceptable with toxic propellants common bulkheads between fuel and oxidizer tanks locating various components inside tanks to obtain packaging and structural advantages using propellant in a heat exchanger to cool pump-drive gas potentially fragile thin-walled tanks designed for low pressure operation spacecraft qualification testing (thermal/vac and vibration) with real propellants mission duty cycle including running thrusters in thermal/vac test. 


\section{References Cited}

Brewster, MR-125 Thruster Life Demonstration Test, Olin Aerospace Co. report 94-R1897, Sep 1994.

Bryant, Knight, Hurtz, Planetary Lander Vehicles Utilizing LEAP Technology, AIAA 942748, 1994.

Burtoft, A small Combustion Chamber for Space Application, JBIS 1965.

Carter \& Smith, Mars Rover Sample Return_Lander Performance, AIAA 89-0633, 1989.

Clapp, A Single Stage to Orbit Rocket with Non-Cryogenic Propellants, AIAA 93-2285, 1993.

Cort, Hurlbert, Riccio, Sanders, Non-Toxic On-Orbit Propulsion for Advanced Space Vehicle Applications, AIAA 95-2974, 1995.

Cunningham, Viking Mars Hydrazine Terminal Descent Engine Thermal Design

Considerations, J. Spacecraft 14:1, January 1977.

Daub, private communication, Lockheed-Martin Astronautics, July 1995

Harrison \& Slocumb, Evaluation of Entry and Terminal Deceleration Systems for Unmanned Martian Landers, J. Spacecraft 6:10, October 1969.

Kirk, Intrieri, Seiff, Aerodynamic Behavior of the Viking Entry Vehicle: Ground Test and Flight Results, J. Spacecraft 15:4, 1978.

Martin-Marietta, The Viking Mission to Mars, circa 1976.

McGrath \& Kirschner, private communications, Thiokol Elkton Division, Fall 1995.

Moog, Bendura, Timmons, Lau, Qualification Flight Tests of the Viking Decelerator System, J. Spacecraft \& Rockets 11:3, March 1974.

NASA, Viking Lander "As Built" Performance Capabilities, NAS1-9000, Jun 1976.

National Research Council, 1990 Update to Strategy for Exploration of the Outer Planets, National Academy Press, National Academy of Sciences.

Pfund, A Case Study in Real-Time Ground Control and Data Processing, J. Spacecraft 6:1, January 1969.

Purohit, Nordeng, Ellison, Loading Operations for Spacecraft Propulsion Subsystems, AIAA 92-3065, 1992.

Richards \& Powell, The Centaur Vehicle, Journal of the British Interplanetary Society, p. 99, 1989.

Rocketdyne, Hydrogen Peroxide Handbook, Technical Report AFRPL-TR-67-144, Air Force Rocket Propulsion Lab, 1967. 
Sanders, Integrated Propulsion and ISRU Propellant Production System for Mars Sample Return, AIAA 95-2641, 1995.

Schappell \& Johnson, Experimental and Simulation Study Results of a Planetary Landing Site Selection System, J. Spacecraft 10:4, April 1973.

Schurmeier, Planetary Exploration: Earth's New Horizon, J. Spacecraft 12:7, July 1975.

Sellers, A Low-Cost Propulsion Option for Small Satellites, J. Brit. Interplanetary Soc. 48:3, March 1995.

Simpkin et. al., KEW Divert Vehicle Propulsion System Technology Verification and Risk Reduction Program, Phases I-V, Volume 1, Air Force Astronautics Laboratory report number AFAL-TR-88-020, 1988.

Soffen, Mars and the Remarkable Viking Results, J. Spacecraft 15:4, July-August 1978.

Taylor \& Faust, Viking Type Spacecraft Rendezvous with the Martian Moons, J. Spacecraft 10:8, August 1973.

Tuckness, Analysis of a Terminal Landing on Mars, J. Spacecraft 32:1, Jan-Feb 1995.

Weaver, Mars Surface-to-Orbit Vehicles for Sample Return Missions, J. Spacecraft 11:6, June 1974.

Whitehead, Pittenger, Colella, Design and Flight Testing of a Reciprocating Pump Fed Rocket, AIAA 94-3031, July 1994.

Zubrin, Price, Mason, Clark, An End-to-End Demonstration of a Full Scale Mars Sample Return In-Situ Propellant Production Unit, AIAA 95-2798, 1995.

Zubrin, Diborane/CO2 Rockets for use in Mars Ascent Vehicles, JBIS 48:9, p. 387-390, 1995. 


\section{Propulsive Requirements \& Spacecraft Capabilities}

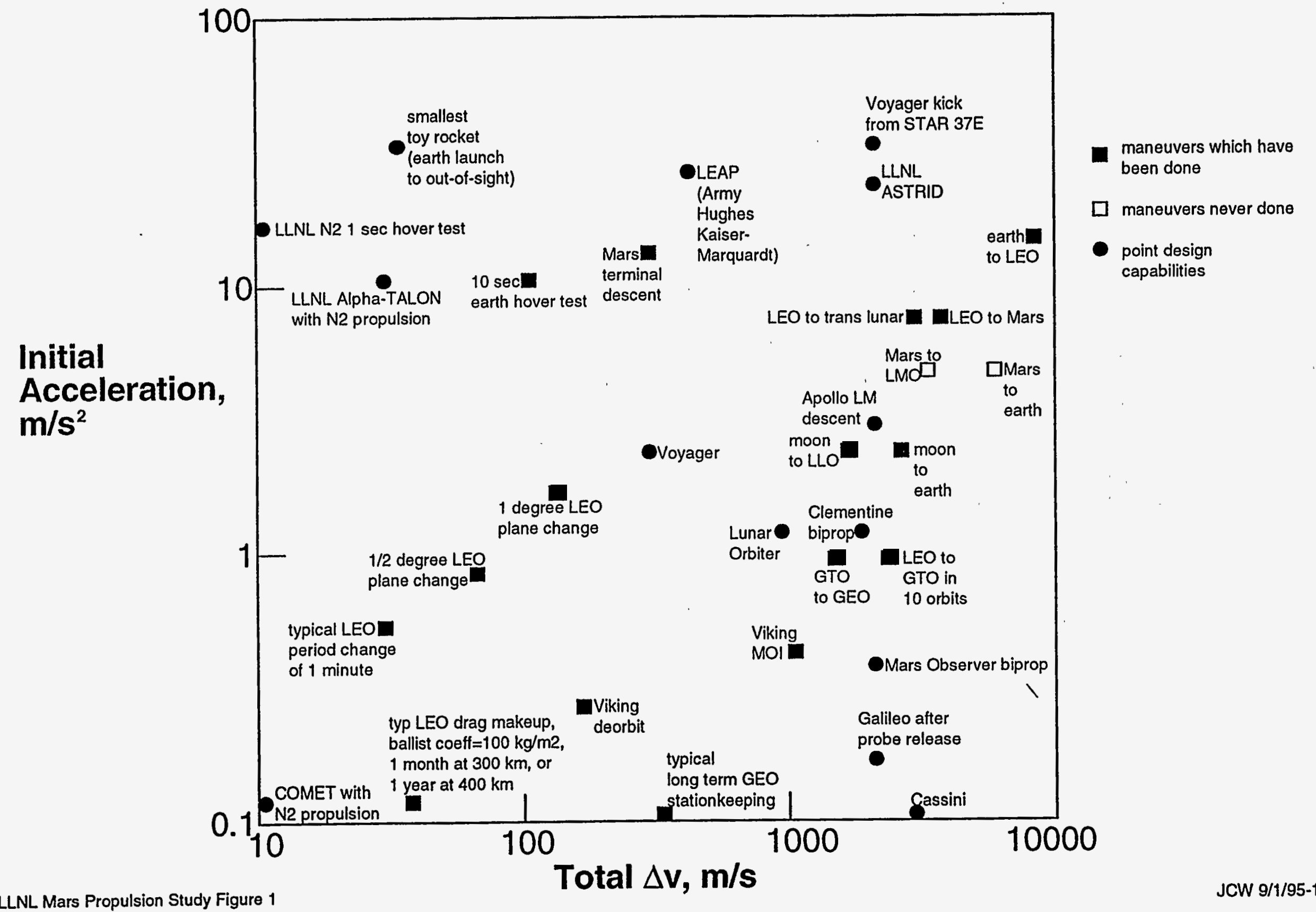




\section{Chemical Propulsion Applicable Technologies}

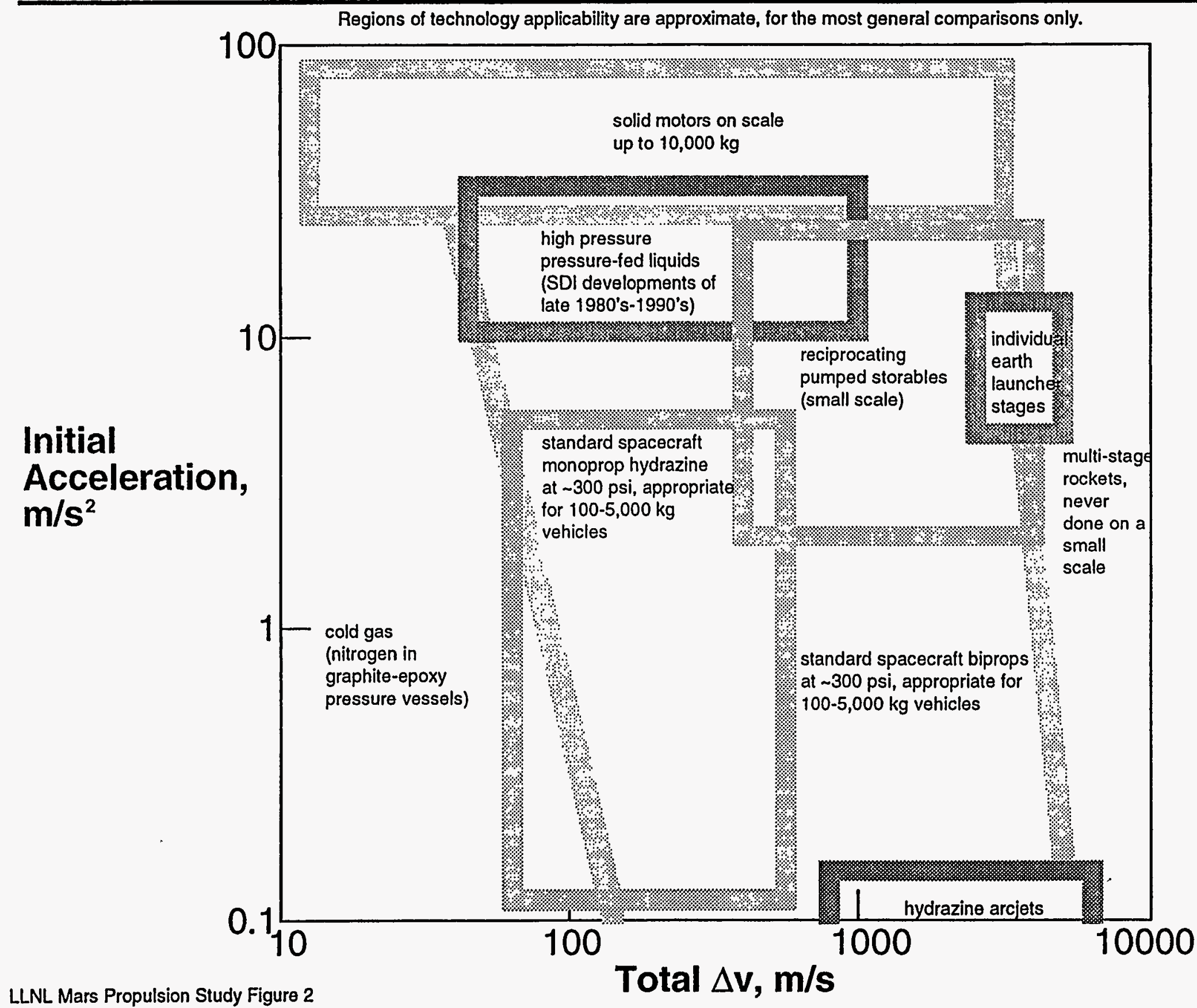




\section{Rocket Engine Pump Performance 1}

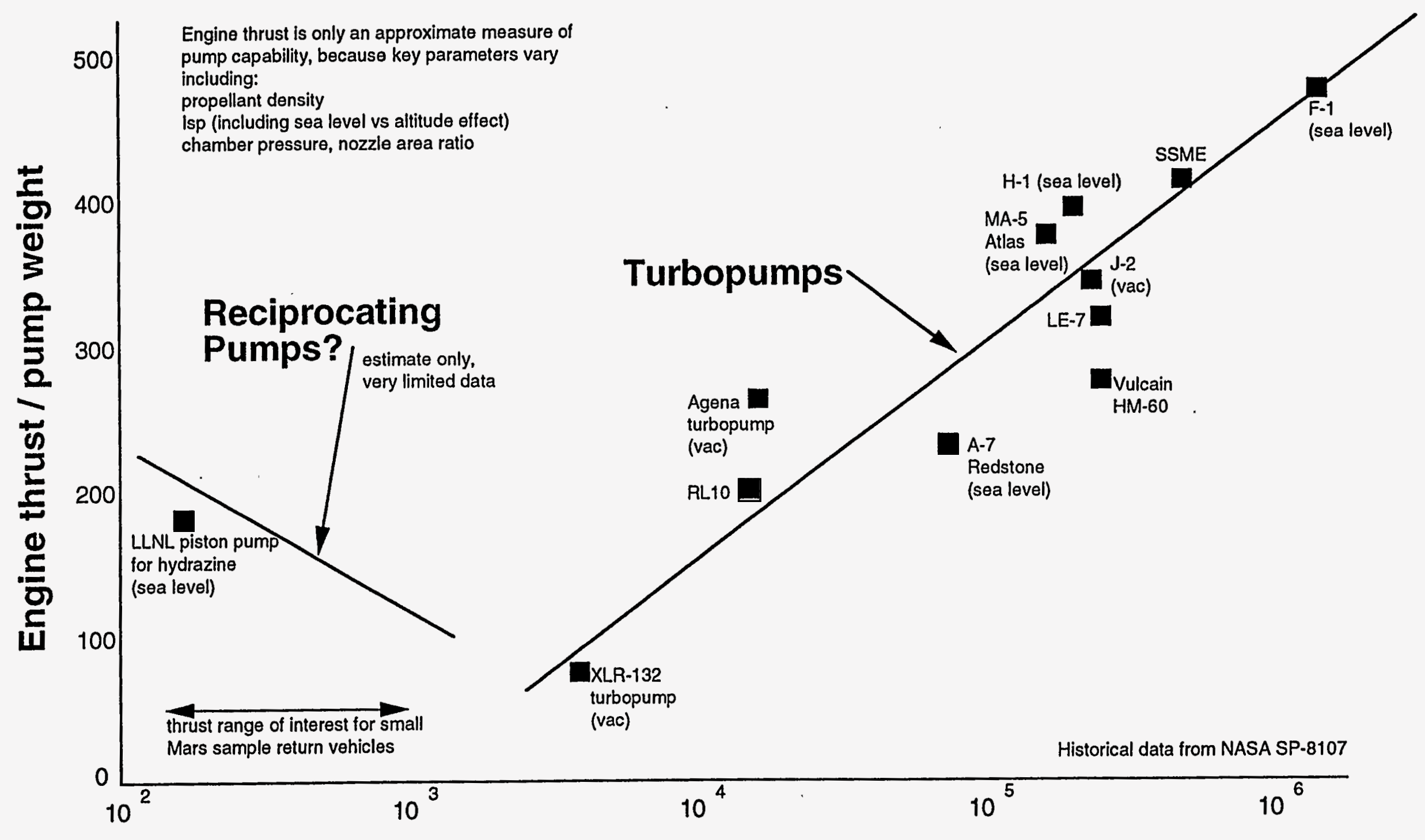

Thrust, lb 


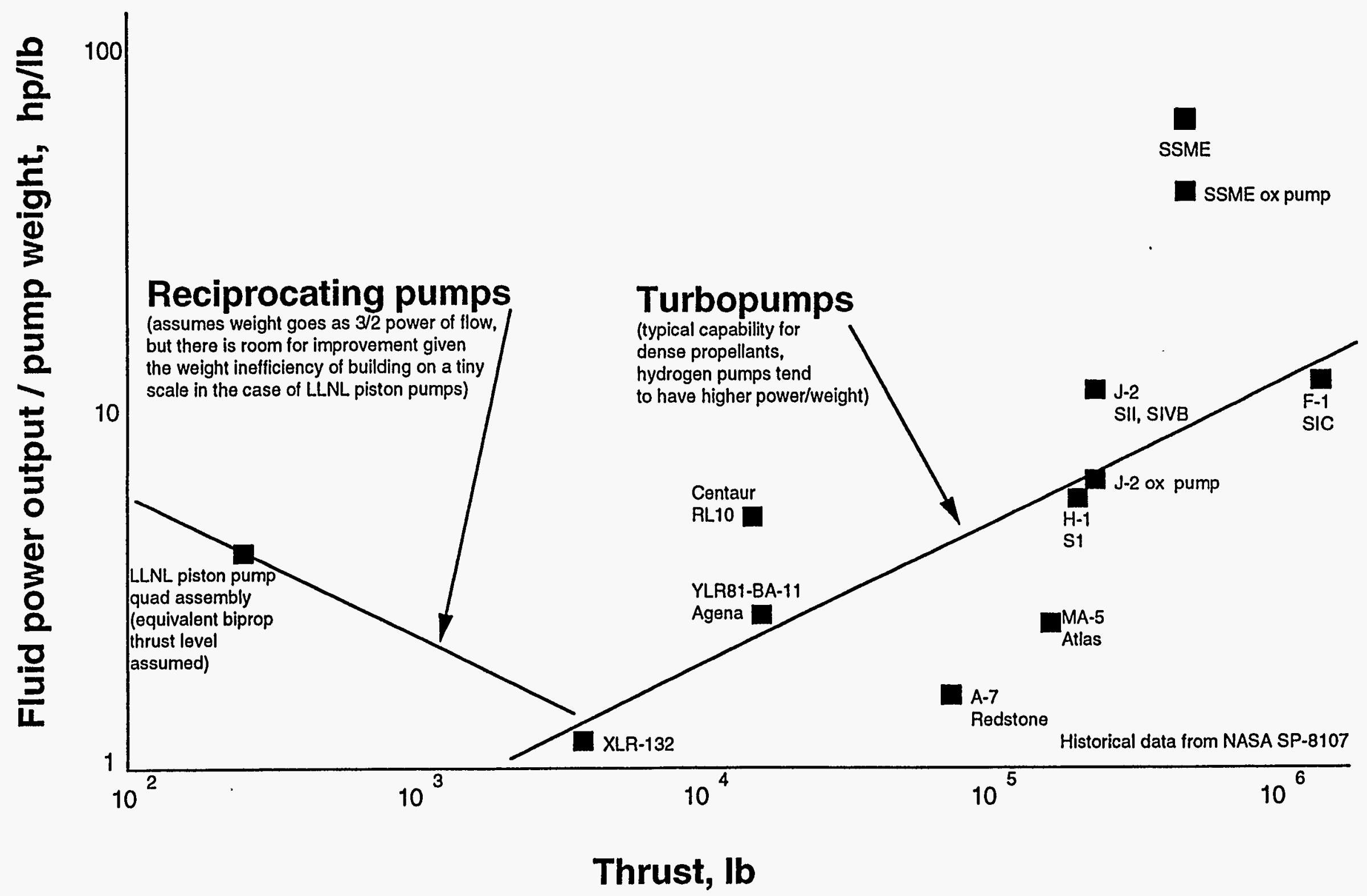




\section{Mars Landing Propulsion for a $\mathbf{1 0 0 ~ k g ~ V e h i c l e ~}$}

$100 \mathrm{~kg}$ landing mass, $350 \mathrm{~m} / \mathrm{s} \Delta \mathrm{v}$, thrust/mass $\geq 10 \mathrm{~m} / \mathrm{sec}-\mathrm{sec}, 1 \% \mathrm{RCS}$

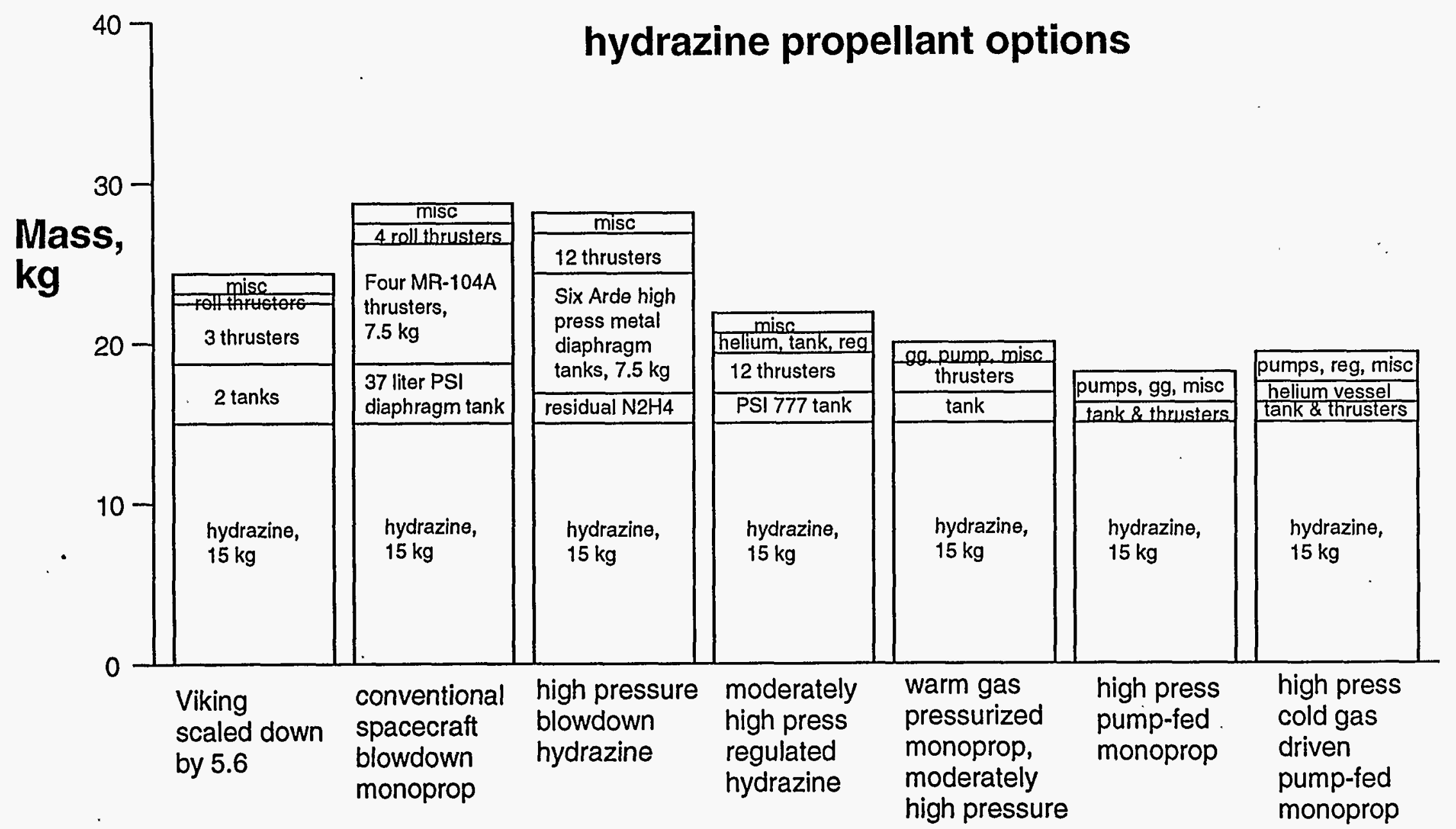

Propulsion Design Option 


\section{More Mars Landing Propulsion for a $100 \mathrm{~kg}$ Vehicle}

$100 \mathrm{~kg}$ landing mass, $350 \mathrm{~m} / \mathrm{s} \Delta \mathrm{v}$, thrust/mass $\geq 10 \mathrm{~m} / \mathrm{sec}-\mathrm{sec}, 1 \% \mathrm{RCS}$

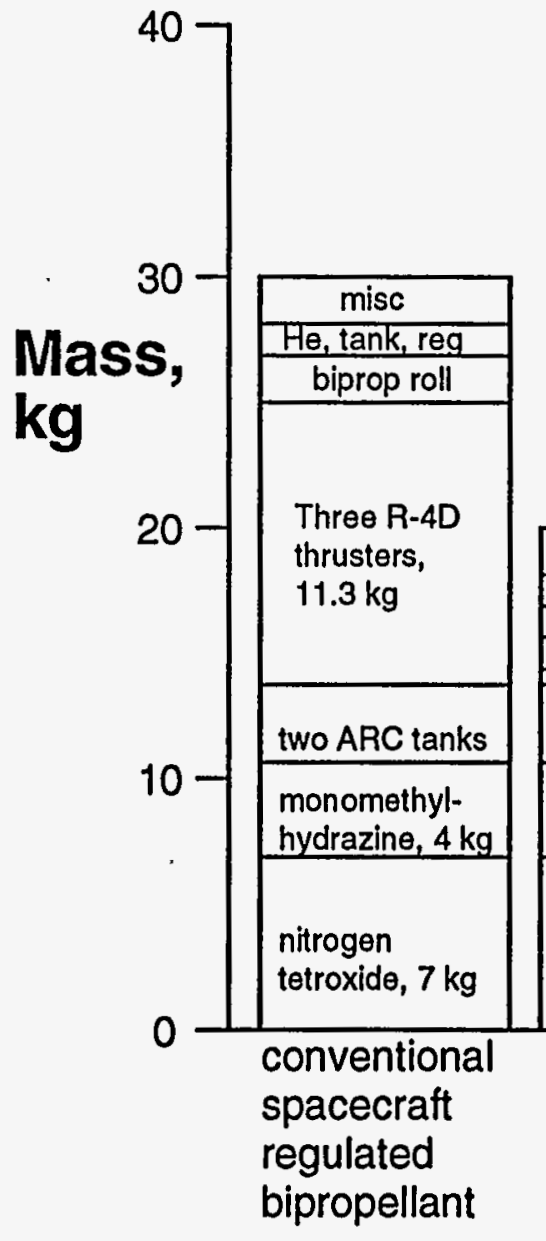

\section{bipropellant and nontoxic propellant options}

\begin{tabular}{|c|}
\hline misc \\
\hline $\begin{array}{c}\text { reg \& roll jets } \\
\text { N2tank }\end{array}$ \\
\hline $\begin{array}{l}\text { nitrogen } \\
\text { nesiens }\end{array}$ \\
\hline $\begin{array}{l}8 \text { Arde tanks, } \\
\text { D4272 }\end{array}$ \\
\hline $\begin{array}{l}\text { monomethyl- } \\
\text { hydrazine, } 4 \mathrm{~kg}\end{array}$ \\
\hline $\begin{array}{l}\text { nitrogen } \\
\text { tetroxide, } 7 \mathrm{~kg} \\
\text { (4.8 liters) }\end{array}$ \\
\hline
\end{tabular}

\begin{tabular}{|c|c|c|c|c|}
\hline & $\begin{array}{c}\text { pump, gg. mise } \\
\text { thrusters }\end{array}$ & pump, g.g., misc & & \\
\hline & $\operatorname{tank}$ & tank \& thrusters & & \\
\hline misc & \multirow{4}{*}{$\begin{array}{l}\text { hydrogen } \\
\text { peroxide, } \\
20 \mathrm{~kg}\end{array}$} & \multirow{4}{*}{$\begin{array}{l}\text { hydrogen } \\
\text { peroxide, } \\
20 \mathrm{~kg}\end{array}$} & \begin{tabular}{|c|} 
pump, gg, misc \\
thrusters
\end{tabular} & pump, gg, misc \\
\hline $\begin{array}{l}\text { pumps \& gg } \\
\text { tanks \& thrusters }\end{array}$ & & & \begin{tabular}{|c|} 
tanks \\
hydrocarbon \\
\end{tabular} & \begin{tabular}{|c} 
tanks \& thrusters \\
hydrocarbon \\
\end{tabular} \\
\hline hydrazine, $4 \mathrm{~kg}$ & & & \multirow{2}{*}{$\begin{array}{l}\text { hydrogen } \\
\text { peroxide, } \\
10.6 \mathrm{~kg}\end{array}$} & \multirow{2}{*}{$\begin{array}{l}\text { hydrogen } \\
\text { peroxide, } \\
10.6 \mathrm{~kg}\end{array}$} \\
\hline $\begin{array}{l}\text { nitrogen } \\
\text { tetroxide, } 7 \mathrm{~kg} \\
\text { (4.8 liters) }\end{array}$ & & & & \\
\hline $\begin{array}{l}\text { high press } \\
\text { pump-fed } \\
\text { bipropellant }\end{array}$ & $\begin{array}{l}\text { warm gas } \\
\text { pressurized } \\
\text { nontoxic } \\
\text { monoprop }\end{array}$ & $\begin{array}{l}\text { high press } \\
\text { pump-fed } \\
\text { nontoxic } \\
\text { monoprop }\end{array}$ & $\begin{array}{l}\text { warm gas } \\
\text { pressurized } \\
\text { nontoxic } \\
\text { bipropellant }\end{array}$ & $\begin{array}{l}\text { high press } \\
\text { pump-fed } \\
\text { nontoxic } \\
\text { bipropellant }\end{array}$ \\
\hline
\end{tabular}

\section{Propulsion Design Option}




\section{Mars Landing Propulsion for a $10 \mathrm{~kg}$ Vehicle}

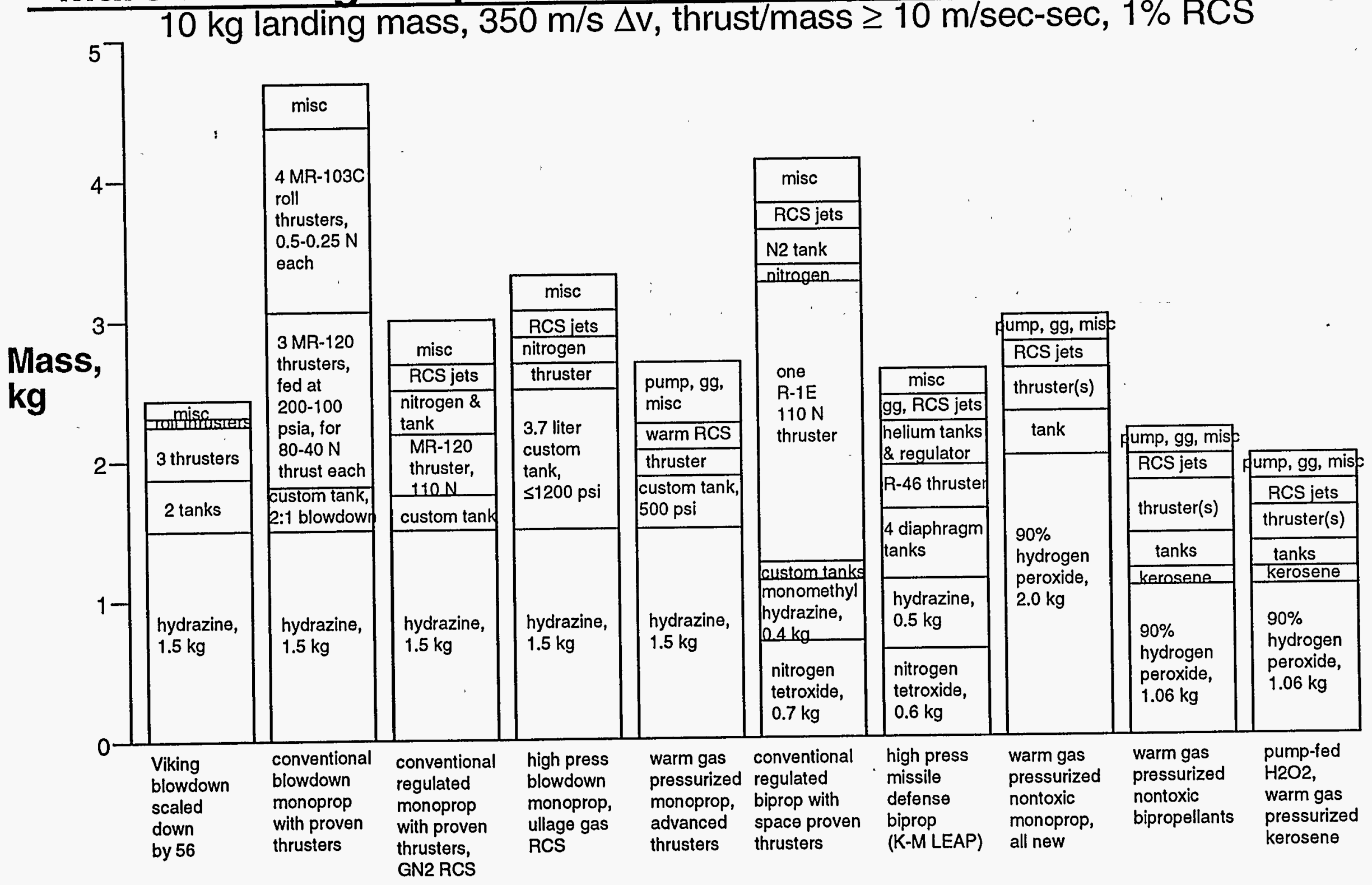

Propulsion Design Option 


\section{First Stage Options for a $100 \mathrm{~kg}$ Mars Launcher}

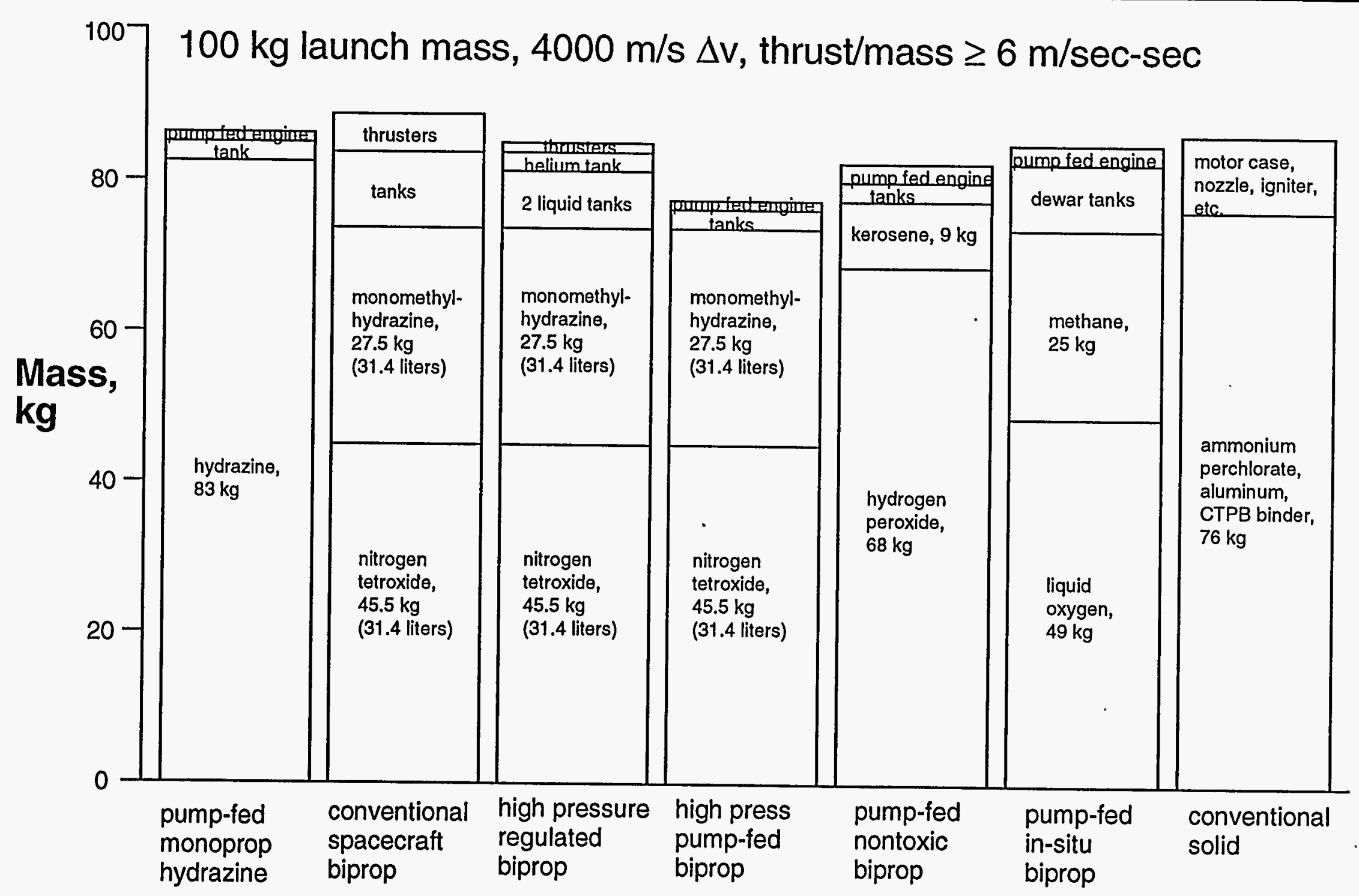

\section{Propulsion Design Option}




\section{Mars Launcher Concept using Nontoxic Propellants}

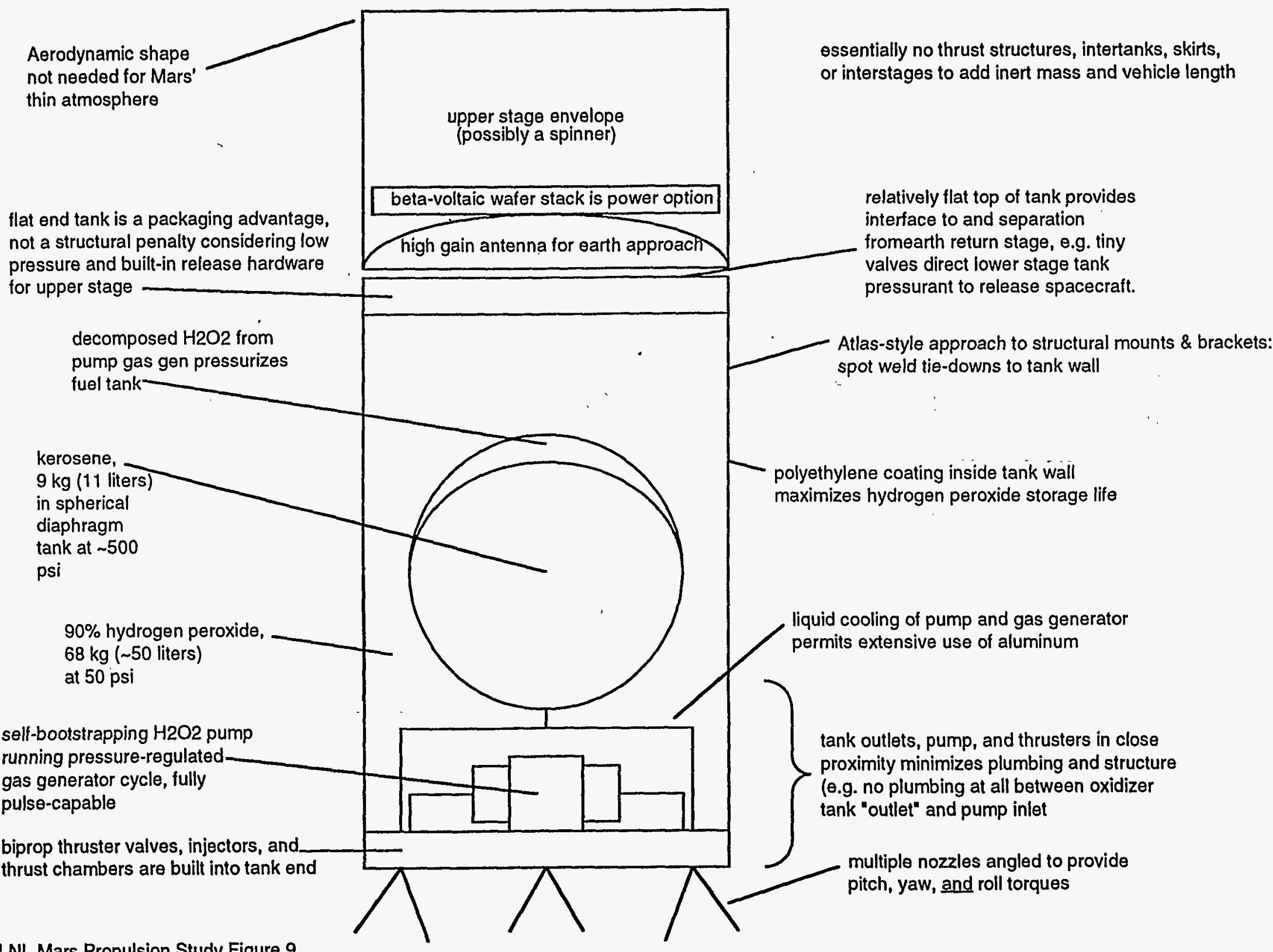





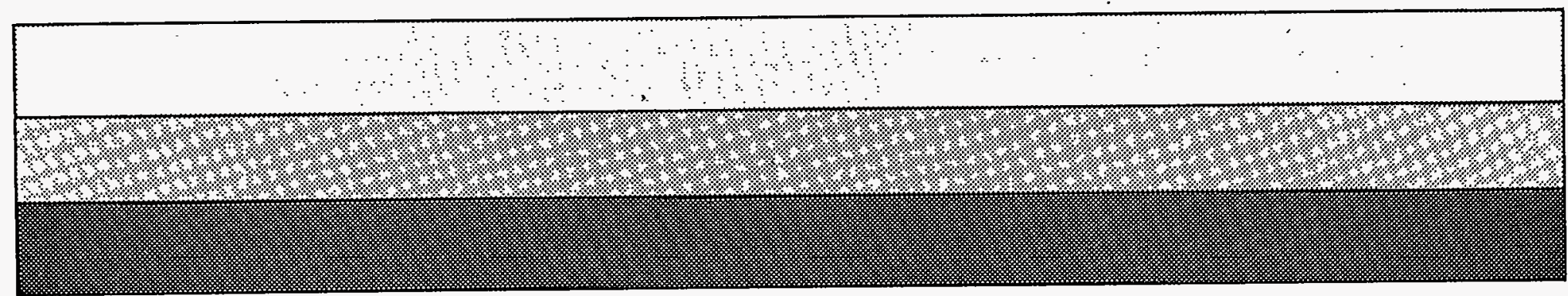

